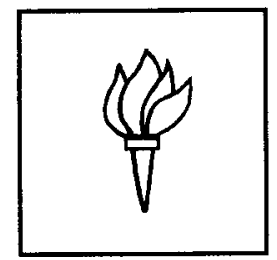

NEW YORK UNIVERSITY

STERN SCHOOL OF BUSINESS

FINANCE DEPARTMENT

Working Paper Series, 1994

Decision Frequency and Synchronization Across Agents: Implications for Aggregate Consumption and Equity Return

Anthony W. Lynch

FD-94-42 

First Draft: 8/15/94

This Draft:11/23/94

\title{
Decision Frequency and Synchronization Across Agents: Implications for Aggregate
}

\section{Consumption and Equity Return}

\author{
by \\ Anthony W. Lynch \\ New York University
}

This paper is a revision of a chapter from my $\mathrm{PhD}$ thesis at the University of Chicago. My committee members, John Cochrane, Kent Daniel, Eugene Fama, Ken French, Lars Hansen and especially my chairman George Constantinides are thanked for their comments and encouragement. Pierluigi Balduzzi, Kobi Boudoukh, Steve Davis, Antti Ilmanen, Johnny Liew, Guillermo Mondino, Thomas Sargent, Robert Whitelaw and participants at workshops at the University of Chicago, Duke University, University of Illinois at Champaign, Ohio State University, Harvard University, UCLA, University of Southern California, University of Texas at Austin and New York University provided many helpful comments. All remaining errors are mine. Address correspondence and reprint requests to Professor Anthony W. Lynch, New York University, 44 West 4th St Suite 9-190, New York NY 10012, ph: 212-9980350. 



\title{
Decision Frequency and Synchronization Across Agents: Implications for Aggregate Consumption and Equity Return
}

\begin{abstract}
This paper examines a model in which decisions are made at fixed intervals and are unsynchronized across agents. Agents choose nondurable consumption and portfolio composition and either or both can be chosen infrequently. A small utility cost is associated with both decisions being made infrequently indicating the plausibility of such behaviour. Calibrating returns to the U.S. economy, less frequent but synchronized consumption decision-making delivers the low correlation of aggregate consumption growth and equity return found in the data. Introducing nonsynchroneity delivers the low volatility of aggregate U.S. consumption growth as well. The incremental effect of less frequent and unsynchronized portfolio rebalancing on the joint behavior of aggregate consumption and returns is always found to be negligible.
\end{abstract}





\section{Decision Frequency and Synchronization Across Agents: Implications for Aggregate Consumption and Equity Return}

It is a reasonable characterization of real world individual behavior to say that neither consumption nor investment decisions are made continuously. Further, it is an open question what the appropriate decision interval is for either consumption or investment. Additionally, not all individuals make these decisions at the same time. This paper examines in some detail how the frequency of these decisions and their timing across agents affects the behavior of aggregate consumption and stock returns at various data frequencies.

The documented empirical failure of standard representative-agent consumption-based pricing models (see Hansen and Singleton [1982] and [1983]) provides a motivation for understanding the effects of less frequent and unsynchronized decision-making. A well-known manifestation of this failure is the equity premium puzzle which says that aggregate consumption is too smooth and not sufficiently correlated with equity returns to explain the magnitude of the equity premium for reasonable values of the relative risk aversion (RRA) coefficient (see Mehra and Prescott [1985]). Since less frequent decision-making by its very nature delinks asset returns from consumption, it would seem a promising avenue to explore in explaining the puzzle.

Already papers have discussed how frictions in the asset markets or in the durable goods market cause less frequent and constrained decision-making. One approach examines how borrowing restrictions, short sale restrictions or asset market transaction costs lead to less stringent restrictions being placed on representative-agent intertemporal marginal rates of substitution (IMRSs) than the usual Euler equation restriction (see He and Modest [1991], Luttmer [1992] and Cochrane and Hansen [1992]). The empirical evidence suggests that representative-agent IMRSs still fail to satisfy these weaker restrictions for reasonable RRA values except when several frictions are present at once and high frequency returns are used.

Another line of research tries to understand how an individual makes portfolio rebalancing decisions and durable good purchases in the presence of transaction costs in one or other market but not both. The timing of adjustments is allowed to be a function of information released since the most recent adjustment, leading to state-dependant adjustment rules. Consequently, the interval 
between adjustments varies through time. Constantinides [1986] focuses on the effect of proportional transaction costs to trading the risky asset in the absence of labor income. He finds that individuals sharply reduce the frequency and volume of trade and that the impact on the equity premium is second-order. Grossman and Laroque [1990] consider a model in which consumption services are derived from the stock of a durable good which can only be varied by incurring proportional transaction costs. They find that even small costs can lead to infrequent durable good purchases. In the periods between purchases, consumption services are unrelated to risky asset returns causing the consumption CAPM (capital asset pricing model) to breakdown. Thus, the impact of less frequent decision-making seems to vary depending on whether the decision pertains to the individual's durable good stock or investment portfolio.

An interesting but difficult question is how to characterize aggregate behavior and the crosssection when individuals are using these state-dependant decision rules. Caballero [1993] characterizes the cross-sectional distribution of durable good stock and the behavior of aggregate durable good purchases in an economy where individuals return their durable good stock to the optimal level only when an upper or lower trigger is reached. A similar analysis is performed by Caballero [1992] for nondurables consumption in a model in which individuals keep consumption constant until the deviation of actual from preferred consumption reaches an upper or lower trigger point. Individuals do not have a portfolio formation decision in either model and have to continuously determine the optimal level of durables stock or nondurables consumption.

A third strand of literature performs calibrations to assess how idiosyncratic and uninsurable labor income risk affects the relation between aggregate consumption and the equity premium (see Mankiw [1986], Lucas [1994] and Telmer [1993]). The marginal impact of introducing asset market frictions has also been examined by Heaton and Lucas [1994]. To summarize this evidence, idiosyncratic labor income can not explain the equity premium either alone or in conjunction with asset market frictions unless the frictions create a transaction cost differential across the two markets which directly delivers the premium. ${ }^{1}$

My paper considers a model in which the consumption and portfolio composition decision intervals of individuals are assumed to be constant through time (though not necessarily the same). In contrast to the models discussed above in which agents have state-dependant decision rules, 
characterizing the cross-section is straight forward as individuals fall into classes that depend on when they make decisions; there is a natural sense in which decision-making across agents is staggered. ${ }^{2}$ Agents do not receive labor income in the model so the results are not being driven by the presence of uninsurable idiosyncratic income shocks.

The model's decision-structure is imposed exogenously without specifying the reason for the less frequent decision-making. Although not explicitly modelled, it is envisaged that consumers face certain costs which lead them to make less frequent decisions concerning the pattern of nondurable consumption and portfolio composition. Decision intervals whose lengths are known at their start arise naturally when it is costly to gather information and solve optimization problems. Duffie and Sun [1990] present a model of this type and show that if utility is power, risky asset return is geometric Brownian motion and transaction costs are proportional, the optimal decision interval is a constant. This type of decision structure can be contrasted with the state-dependant decision structures discussed above which are induced by costless information processing and proportional adjustment costs. My model assumes people react to wealth shocks only at fixed intervals while these models assume people continually update their wealth in deciding whether to make an adjustment. These two mechanisms are quite different.

Although there are common forces causing individuals' behavior to be synchronized, my model recognizes that idiosyncratic considerations cause some people to be out of synch with the majority. For example, agents may make annual decision after annual income shocks which occur in different months across individuals. Also, individuals receiving a tax refund prefer to make decisions in January while those owing taxes wait until April. Though the economies considered below treat the decision classes symmetrically, it would be straight-forward to allow the classes to be of unequal sizes. Doing so would introduce seasonality into consumption moments and could potentially explain the seasonal patterns which exist in U.S. nonseasonally-adjusted consumption numbers (see Ferson and Harvey [1992]).

My model allows several previously ignored questions to be considered. Its simple decision structure allows examination of the effects of infrequent portfolio rebalancing both alone and incremental to the effect of less frequent consumption decision-making. Further, its simple crosssectional distribution allows the separate effects of less frequent decision-making and staggering to 
be assessed. Finally, attention can focused on how these effects change as the data frequency is varied.

The model has other advantages and potential applications. The asset pricing implications are susceptible to empirical testing using aggregate consumption (see Lynch [1994] for a discussion and some results). As discussed above, seasonalities in consumption can be generated by such a model. Finally, the model is likely to be useful for analyzing the impact of infrequent and unsynchronized decision-making on monthly asset return autocorrelations.

The paper has several results, many of them new, which are obtained by simulating economies with linear production technologies. Throughout, unless otherwise stated, the processes followed by the risky return and the riskless rate remain the same and are calibrated to the U.S. economy. The first result pertains to the impact on low frequency data of the representative-agent making less frequent decisions. It is found that when the agent makes decisions monthly rather than annually, the volatility of annual aggregate consumption growth declines by about $19 \%$. This percentage decline can be viewed as a direct measure of the effect of temporal aggregation. ${ }^{3}$

The second result concerns the effect of infrequent and staggered decision-making on the relation between aggregate consumption and risky asset returns. Less frequent and staggered portfolio rebalancing together with monthly consumption decision-making has virtually no effect on the volatility of aggregate consumption growth and its correlation with risky asset return relative to the monthly decision-making, representative-agent case. So Constantinides' [1986] result that proportional transaction costs on the risky asset has a second order effect on the equity premium seems robust to more severe cost structures which do not allow state-dependant decision intervals.

Conversely, less frequent and staggered consumption decision-making causes reductions in the volatility of aggregate consumption at monthly frequencies and in its correlation with equity return at monthly, quarterly and annual frequencies. In fact, the volatility of monthly aggregate consumption growth is lower than the data for a \{RRA coefficient, consumption decision interval\} pair of $\{8,12$ months $\}$ or $\{10,6$ months $\}$. This is one of the key results of the paper. Notice that there is no idiosyncratic labor income contributing to the volatility reductions. Further, the magnitude of the percentage reduction (relative to the monthly decision-making representative-agent model) of either the standard deviation or correlation depends only on the decision interval. Adding 
a second risky asset or varying the RRA coefficient does not affect the magnitude of the reduction as long as the decision interval is fixed.

The third result relates to interaction effects when both decisions are made infrequently. If both decisions are made less frequently but simultaneously by each individual but with nonsynchroneity across individuals (a staggered decision interval SDI model), the results are virtually identical to those obtained when only the consumption decision is made less frequently.

Fourth, the incremental impact of the staggering is directly assessed by comparing the moments for aggregate consumption growth in an SDI model with those for the consumption of a chosen class in the same economy. Less frequent decision-making alone has almost no effect on consumption growth volatility while causing large declines in its correlation with risky asset return. The incremental effect of the staggering is to cause this volatility to decline while leaving the covariance with risky asset return unaffected. ${ }^{4}$ Thus, infrequent decision-making reduces the correlation of consumption growth with risky asset return while decision nonsynchroneity across agents causes the volatility reductions.

Fifth, the paper considers the impact of less frequent and staggered decision-making in an SDI model as the data frequency is varied relative to the decision interval. This relative frequency of the data is the crucial determinant of less frequent decision-making's impact on aggregate consumption growth volatility. The largest volatility reductions are for the highest frequency data with the reductions declining to marginally less than the monthly decision-making, representativeagent case as the data frequency approaches the decision interval. Since the longest decision interval considered is a year, this explains why the reduction in the volatility of annual aggregate consumption growth induced by less frequent consumption decision-making is small. In contrast, aggregate consumption growth's correlation with risky asset return declines monotonically with decision interval irrespective of data frequency. For any given decision interval greater than one month, the correlation has a u-shape as the data frequency varies.

Finally, the utility cost of less frequent consumption and investment decision-making is found to be very small. If an individual was making decisions every 6 (12) months, she would not give up more than $0.5 \%(1 \%)$ of her wealth as a one-off cost to be allowed to make decisions every month. Importantly, very small costs are associated with decision intervals that are able to 
significantly reduce aggregate consumption growth volatility and its correlation with equity return. ${ }^{5}$

The paper is organized as follows. Section 1 describes the various economies that are calibrated while simulation details and the data used to calibrate the economies is described in Section 2. The issues addressed and the methodologies for addressing them are presented in section 3 while section 4 discusses the results. Section 5 considers the utility cost of less frequent decisionmaking and section 6 concludes.

\section{The Overlapping Generations Calibration Models.}

Most of the calibration literature uses power utility (see for example, Mehra and Prescott [1985] and Heaton and Lucas [1992],[1994]) and this specification is also employed here. Throughout the analysis the temporal unit of measure is a month; so one period is equal to one month. The age structure and endowment process for the economy is the same for all the models considered. Except when a second risky asset is added, the opportunity set is also the same across models.

Although the models differ in the assumed decision structure for individuals, the decision intervals for consumption and portfolio rebalancing are always constants (denoted $T_{C}$ and $T_{I}$ respectively). Three decision structures for individuals are examined: 1) consumption and investment decisions are made simultaneously by each agent but less frequently than every consumption date (which gives a SDI model): $\mathrm{T}_{\mathrm{C}}=\mathrm{T}_{\mathrm{P}}>1 ; 2$ ) only consumption decisions are made infrequently: $T_{C}>1$ and $T_{I}=1$; and, 3) only investment decisions are made infrequently: $T_{P}>1$ and $T_{C}=1$. For the remainder of the paper, the symbol $\mathrm{T}$ without a subscript is used when both decisions are being made every $T$ periods (the SDI economy). With $\mathrm{T}_{\mathrm{I}}=\mathrm{T}_{\mathrm{C}}=1$ in this model, staggering disappears and is replaced by a monthly decision-making representative-agent.

In each model, at least one decision is made infrequently and only a fraction of the population make that decision at each date. Letting $\mathrm{T}$ be the relevant decision interval, there are $\mathrm{T}$ classes of agent where class membership depends on when an individual trades. Figure 1 shows the decision timing for each of the T classes.

To ensure that aggregate consumption growth has a stationary distribution, an overlappinggeneration-style economy is specified where individuals have finite lives. More precisely, there are 
TxL investors alive at any point in time; $\mathrm{T}$ is the number of periods (here months) between decisions (replace $T$ with $T_{C}$ or $T_{I}$ depending on the model), and $L$ is the number of decisions an individual makes in her lifetime. So TL is the number of months an individual lives. Individuals are indexed by $\mathrm{i}=0,1,2, \ldots, \mathrm{T}-1$ (indicating the individual's decision-making class) and by $\ell=0,1,2, \ldots, \mathrm{L}-1$ (indicating the individual's generational class). An individual of type $(i, \ell)$ is born at $(w L+\ell) T+i$ for each $w$ an integer, and then makes decisions at $\mathrm{L}$ points in time, each $\mathrm{T}$ apart: $(w L+\ell) T+i,(w L+\ell+1) T+i, \ldots,(w L+\ell+L-1) T+i$. So at any point in time there is one individual of each type alive. The starting wealth for newborn individuals grows deterministically at a rate $\mathrm{g}$ per period ensuring a stationary distribution for aggregate consumption: ${ }^{6}$

$$
W^{i,}([w L+l] T+i)=W(0) g^{([w L-\eta T \cdot+)} .
$$

\subsection{The Consumer's Problem with Both Decisions made Infrequently (the SDI model).}

The key feature of the consumer's problem is that consumption and investment decisions are made simultaneously every $\mathrm{T}$ periods. Consumption within a decision interval is determined at the start of the interval while portfolio rebalancing only occurs at the start of an interval. In particular, individuals consume out of the riskless asset within each decision interval.

More formally, the $(i, \ell)$ individual born at $(w L+\ell) T+i$ solves the following problem:

$$
\max \left\{E_{[w L \cdot \eta] \cdot i}\left[\sum_{q=0}^{L T-1} \beta^{q} \frac{1}{1-\gamma}\left[c^{i, r}([w L+l] T+i+q)\right]^{1-\gamma}\right]\right\}
$$

with respect to

$$
\left\{c^{i, i}([w L+l] T+i+q)\right\}_{q-0}^{L T-1}, \text { and },\left\{\alpha^{i,}([w L+l+j] T+i)\right\}_{j=0}^{L-1}
$$

and subject to

$$
\begin{aligned}
& c^{i, l}([w L+l+j] T+i+\hat{q}) \in \mathscr{F}([w L+l+j] T+i), \hat{q}=0,1, \ldots, T-1 \text { and } j=0,1, \ldots, L-1 ; \\
& \alpha^{i, l}([w L+l+j] T+i) \in \mathscr{F}([w L+l+j] T+i), j=0,1, \ldots, L-1 ; \\
& W^{i, l}[[w L+l+j+1] T+i)=\left[W^{i, l}([w L+l+j] T+i)-\hat{c}^{i, l}([w L+l+j] T+i)\right] \\
& {\left[\alpha^{i, l}([w L+l+j] T+i)\left(R^{2}([w L+l+j] T+i,[w L+l+j+1] T+i)-R^{T}\right)+R^{T},\right.}
\end{aligned}
$$

and 


$$
\hat{c}^{i, l}([w L+l+j] T+i)=\sum_{q=0}^{T-1} R^{-q} c^{i, l}([w L+l+j] T+i+q) \quad \text { for } j=0,1,2, \ldots, L-1
$$

where $\gamma>0, \neq 1$ is the RRA coefficient, $B>0$ is the rate of time preference, the riskless rate $R$ is constant, the risky asset return $\mathrm{R}^{\mathrm{z}}$ is i.i.d., $\mathscr{F}(t)$ is the filtration generated by $\left\{\mathrm{R}^{\mathrm{z}}(\mathrm{t}-1, \mathrm{t}), \mathrm{R}^{\mathrm{z}}(\mathrm{t}-2, \mathrm{t}-1)\right.$, $\ldots\}$ and $(i, \ell)$ 's wealth when newborn $\mathrm{W}^{\mathrm{i},}([\mathrm{wL}+\ell] \mathrm{T}+\mathrm{i})$ is given by (1). The solution to this problem applies standard results for the constant opportunity set problem with constant RRA utility (see Ingersoll [1987]). Details are presented in the appendix.

\subsection{The Consumer's Problem when only the Consumption Decision is Made Infrequently.}

In the second overlapping generations economy considered, only the consumption decision is made infrequently. Consumption within a decision interval is determined at the start of the interval as in the previous model but portfolio rebalancing occurs every period. Setting $T_{C}=T$, the $(\mathrm{i}, \ell)$ individual born at $(w \mathrm{w}+\ell) \mathrm{T}+\mathrm{i}$ now maximizes $(2)$ with respect to

$$
\left\{c^{i, l}([w L+l] T+i+q)\right\}_{q-0}^{L T-1}, \text { and },\left\{\alpha^{i, l}([w L+l] T+i+q)\right\}_{q-0}^{L T-1}
$$

and subject to

$$
\begin{aligned}
& c^{i, l}([w L+l+j] T+i+\hat{q}) \in \mathscr{F}([w L+l+j] T+i), \hat{q}=0,1, \ldots, T-1 \text { and } j=0,1, \ldots, L-1 ; \\
& \alpha^{i, l}([w L+l] T+i+q) \in \mathscr{F}([w L+l] T+i+q), q=0,1, \ldots, L T-1 ;
\end{aligned}
$$

$$
\begin{array}{r}
W^{i, l}([w L+l+j] T+i+1)=\left[W^{i, l}([w L+l+j] T+i)-\hat{c}^{i, l}([w L+l+j] T+i)\right] \\
{\left[\alpha^{i, l}([w L+l+j] T+i)\left(R^{z}([w L+l+j] T+i,[w L+l+j] T+i+1)-R\right)+R\right] ; \text { and }} \\
W^{i, l}([w L+l+j] T+i+\hat{q}+1)=W^{i, l}([w L+l+j] T+i+\hat{q}) \\
{\left[\alpha^{i, l}([w L+j+j] T+i+\hat{q})\left(R^{z}([w L+l+j] T+i+\hat{q},[w L+l+j] T+i+\hat{q}+1)-R\right)+R\right]} \\
j=0,1, \ldots, L-1 ; \text { and }, \hat{q}=1,2, \ldots, T-1 ;
\end{array}
$$

and

$$
\hat{c}^{i, l}([w L+l+j] T+i)=\sum_{q=0}^{T-1} R^{-q} c^{i, l}([w L+l+j] T+i+q) \quad \text { for } j=0,1,2, \ldots, L-1
$$

where (i,l)'s wealth when newborn $\mathrm{W}^{\mathrm{i}, \ell}([\mathrm{wL}+\ell] \mathrm{T}+\mathrm{i})$ is given by (1). There is a closed form solution to this problem that exploits results for the constant opportunity set problem with power utility (see Ingersoll [1987]). 


\subsection{The Consumer's Problem when only the Investment Decision is Made Infrequently.}

In this third overlapping generations economy, consumption is determined every period while risky asset holdings can only be adjusted at the start of each decision interval. Consumption adjustments within a decision interval are made out of the riskless asset.

Again setting $\mathrm{T}_{\mathrm{l}}=\mathrm{T}$, the $(\mathrm{i}, \ell)$ individual born at $(\mathrm{wL}+\ell) \mathrm{T}+\mathrm{i}$ now maximizes $(2)$ with respect to

$$
\left\{c^{i, l}([w L+l] T+i+q)\right\}_{q=0}^{L T-1}, \text { and },\left\{\alpha^{i, l}([w L+l+j] T+i)\right\}_{j-0}^{L-1}
$$

and subject to

$$
\begin{gathered}
c^{i, l}([w L+l] T+i+q) \in \mathscr{F}([w L+l] T+i+q), q=0,1, \ldots, L T-1 ; \text { and }, \alpha^{i, l}([w L+l+j] T+i) \in \mathscr{F}([w L+l+j] T+i), j=0,1, \ldots, L-1 ; \\
X^{i, l}([w L+l+j] T+i)=W^{i, l}([w L+l+j] T+i) \alpha^{i, l}([w L+l+j] T+i), \text { and, } \\
X^{i, l}([w L+l+j] T+i+\hat{q}+1)=X^{i, l}([w L+l+j] T+i+\hat{q}) R^{z}([w L+l+j] T+i+\hat{q},[w L+l+j] T+i+\hat{q}+1), \\
j=0,1, \ldots, L-1 ; \text { and }, \hat{q}=0,1, \ldots, T-1 ;
\end{gathered}
$$

and

$$
\begin{array}{r}
W^{i, l}([w L+l] T+i+q+1)=\left[W^{i, l}([w L+l] T+i+q)-X^{i, l}([w L+l] T+i+q)-c^{i, l}([w L+l+j] T+i+q)\right] R+X^{i, l}([w L+l] T+i+q+1) \\
\text { for } q=0,1, \ldots, L T-1 ;
\end{array}
$$

where $(i, \ell)$ 's wealth when newborn $\mathrm{W}^{\mathrm{i}, \ell}([\mathrm{wL}+\ell] \mathrm{T}+\mathrm{i})$ is given by (1). Although it is not possible to get a closed form solution to this problem, the appendix describes how the problem can be solved numerically.

\section{The Calibration Exercise.}

The next section describes the data used to calibrate returns while the subsequent section presents details of how the various economies are simulated.

\subsection{Data Used to Calibrate Returns.}

The sample moments used to calibrate the Binomial process for the risky asset are calculated for the monthly real return on a value weighted NYSE index derived from the CRSP index files. The real riskless rate is estimated using the mean of the month-t return on the shortest term U.S. treasury bill having not less than one month to maturity; this series is obtained from CRSP. For 
comparison purposes, sample moments for growth in aggregate consumption are also reported. The monthly aggregate consumption series is obtained by deflating monthly nondurable consumption and monthly services consumption by their respective price deflators and by population and then taking the sum. The implicit price deflator for this derived nondurable and services consumption series is also used to deflate the nominal asset returns. Data from $1 / 59$ to $12 / 91$ is then used to calculate moments for NYSE real return and growth in aggregate consumption at monthly, quarterly and annual frequencies. ${ }^{7}$ Results are contained in Table 1.

\subsection{Simulation Details.}

In all the simulations with a lone risky asset, it's return evolves according to a Binomial process with each state equally likely. To match the mean and variance of the NYSE value weighted index return reported in Table 1, the monthly risky asset return took values of 1.0492 and 0.9615 in the two states. The average real U.S. Treasury bill rate (reported in Table 1) which was 1.0011 over the sample period is used as the riskless rate. In all the overlapping generations models, the assumed value for the growth of the newborn's initial wealth is 1.002 and a rate of time preference of 1 is used.

Two of the overlapping generations models are calibrated for RRAs of 5,8 and 10 and decision intervals of 1, 3,6 and 12: the model in which both decisions are made infrequently and the model in which only the consumption decision is made less frequently (every $\mathrm{T}_{\mathrm{C}}$ periods). For the model in which only the investment decision is made less frequently, calibrations are performed for RRAs of 5 and 8 and investment decision intervals (denoted $T_{1}$ ) of 1,2 and 3; for longer decision intervals, the large number of states made choice of starting values crucial to being able to

numerically solve the consumer's problem. Five simulations each with 10000 usable observations are used to calculate the moments for each economy. ${ }^{8}$

A version of the SDI economy ( Section 1.1) with two risky assets is also simulated. The two risky asset returns are assumed i.i.d. and allowed to evolve according to a four state Multinomial process with each state equally likely. Return realizations are chosen so that the first asset has the same distribution as the lone risky asset and the second asset's return has a mean of 1.0023 and no skewness. The variance of the second asset's return and its correlation with the first asset's return 
are varied across the simulations. The first asset can be treated as an equity return since its mean and variance are chosen to match the NYSE sample moments. The mean of the second asset's return is based on the average real capital gain return for real estate from 1953-1971 reported as 0.9998 in Table 2 of Fama and Schwert [1977]. Net rental return is estimated at 0.0025 and added to the capital gain return to get the mean of 1.0023 . So the second asset can be loosely regarded as a real estate return.

It is worth noting that the calibration exercise specifies an exogenous return process and then solves for consumption. Thus, the calibration framework is in the spirit of Constantinides [1990] and can be contrasted with the alternate approach of specifying the endowment process exogenously and solving for the market-clearing prices (See, for example, Mehra and Prescott [1985]). However, my paper's approach can be put in a general equilibrium framework by saying (in the two asset case) that there are two linear technologies, one riskless and the other risky, both in perfectly elastic supply.

\section{Issues Addressed by the Calibration Exercise.}

The overlapping generations economies described above are used to examine a number of issues which are described in this section.

\subsection{Temporal Aggregation.}

The first issue addressed is the impact of temporal aggregation in a representative agent setting. Moments for a representative-agent economy where the agent makes decisions every $\mathrm{T}$ periods are obtained as follows. For the overlapping generations economy in which agents make both decisions every $\mathrm{T}$ periods, one class's monthly consumption series is treated as aggregate consumption. Then moments for a given frequency $(s 1 / T)$ are obtained by summing consumption over intervals that always start and end with a decision by the class. So when the data frequency equals $1 / \mathrm{T}$, non-overlapping consumption numbers are being used to calculate the moments. Temporal aggregation can be examined by selecting a low frequency (say 1/12) and allowing the agent's decision interval to become shorter. 


\subsection{Impact of Staggered and Less Frequent Decision-making.}

The second issue to be addressed is the impact of staggered and less frequent decisionmaking on aggregate consumption growth volatility and its correlation with equity return. For a given data frequency, this joint impact can be assessed by examining the behavior of these moments for the SDI model of Section 1.1 as the decision interval $\mathrm{T}$ is increased.

A useful measure is the ratio of a particular moment for a given $\mathrm{T}$ to the same moment with $\mathrm{T}=1$. Since $\mathrm{T}=1$ means decisions are being made every period, this ratio is a direct measure of what happens to the moment when the decision interval is increased to $T$ in the presence of staggering across agents.

\subsection{Data Frequency Relative to Decision Frequency.}

The third concern is how the impact of less frequent decision-making varies with the frequency of consumption growth being considered. Intuition suggests that it is the frequency relative to decision interval which determines the magnitude of consumption growth volatility relative to the $\mathrm{T}=1$ case. To assess this intuition, the SDI model of Section 1.1 is simulated for an RRA of 5 and $T=1,3,6,12$. Moments are estimated for data intervals of $F=1,2, \ldots, 12$.

\subsection{Impact of Staggering vs Impact of Less Frequent Decision-making: Two Decompositions.}

As discussed above, the joint effect of less frequent and nonsynchronous decision-making is assessed by examining the behavior of aggregate consumption growth volatility and its correlation with risky asset return for a given data frequency as $\mathrm{T}$ the decision interval is increased. The fourth task is to decompose this joint effect into the separate effects of less frequent decision-making and of staggering. Two decompositions are presented. The first compares the moments from the representative agent model for a given $T$ with the same moments when $T=1$. The difference between the two is treated as the effect of less frequent decision-making. Comparing the representative agent moments for a given $\mathrm{T}$ with the SDI aggregate consumption moments for the same $\mathrm{T}$ gives the effect of staggering.

The second decomposition utilizes moments calculated for the consumption of one class 
averaged over all possible timings at a given frequency. So moments are obtained by averaging over all overlapping observations from the simulated series. ${ }^{9}$ These moments for one class are obtained in exactly the same way as moments for aggregate consumption are obtained except consumption of the chosen class is used instead. ${ }^{10}$ Figure 2 compares the consumption numbers used to calculate these moments with the representative-agent consumption numbers: Panel $A$ considers a data frequency $1 / \mathrm{F}$ of $1 / 3$ while Panel $B$ considers $\mathrm{F}=12$. The difference between these moments and those obtained when $T=1$ is treated as the effect of infrequent decision-making under this decomposition. The effect of staggering is the difference between these moments and the SDI aggregate consumption moments for the given $\mathrm{T}$.

These two decompositions can be viewed as complementary. The representative-agent based decomposition is careful to match the consumption interval to the decision interval when assessing the effect of infrequent decision-making alone. It is consistent with the econometrician knowing when decisions are made and only using consumption numbers over intervals that coincide with the decision intervals of the agents. The other decomposition is based on moments that would be obtained by an econometrician using overlapping data in an economy with only one class of decision-makers. It is consistent with the econometrician either thinking decisions are made every period, thinking the economy is an SDI economy, or not knowing exactly when agents make their decisions.

\subsection{Separate Impacts of Less Frequent Investment Decision-making and of Less Frequent Consumption Decision-making.}

It would be useful to know whether infrequent consumption decision-making or infrequent investment decision-making is driving the results for the SDI economy described in Section 1.1. Further, it may be the case that the impact on the moments when both decisions are made infrequently is greater than the sum of the effects when only one decision is made infrequently. In other words, there may be interactions between the two decisions. These questions can be assessed by comparing the aggregate consumption moments obtained for the three economies described above. 


\subsection{Less Frequent and Staggered Decision-making with a Second Risky Asset.}

Finally, the impact of less frequent and staggered decision-making in the presence of a second risky asset is a question of some interest. In particular, does the correlation of aggregate consumption growth with the first risky asset vary with $\mathrm{T}$ in the same way as in the one risky asset case? This question is addressed by comparing the results for the one risky asset and two risky asset versions of the SDI economy of Section 1.1.

Again, a useful measure is a particular moment for a given $\mathrm{T}$ expressed as a ratio of its value for $\mathrm{T}=1$. The ratio's value for a given moment and decision interval $\mathrm{T}$ in the two risky asset version can be compared to its value in the one risky asset version. This ratio captures the incremental effect of infrequent and staggered decision-making and is not contaminated by the effect of the second risky asset's availability on the particular moment, holding the decision interval fixed. This latter effect is netted out by taking a ratio. For example, the presence of a second risky asset is likely to reduce the correlation of aggregate consumption growth with risky asset return for any given $T$. However, the incremental effect of less frequent and staggered decision-making on this correlation may be the same irrespective of the presence of a second risky asset.

\section{$4 \quad$ Calibration Results.}

Table 2 contains the representative-agent results while the results for the overlapping generations models with one risky asset are reported in Tables 3 to 5 , one table for each decision structure. Figures 3 and 4 show what happens as data frequency is varied for the SDI model in which both decisions are made every T periods. Table 6 considers the impact of less frequent decision-making when there is a second risky asset available to the individual.

\subsection{Temporal Aggregation.}

The moments reported in Table 2 are those for the aggregate consumption of a representativeagent economy where power utility individuals live for 20 years and are replaced by newborn, and where all people make decisions simultaneously but less frequently than every consumption date. These moments are virtually identical to those obtained using an infinitely-lived constant RRA representative agent with the same RRA coefficient and holding the opportunity set fixed. ${ }^{11}$ This 
finding shows that the finite life assumption is not driving the representative-agent results and suggests the assumed lifespan for agents in the overlapping generations models is not an important determinant of the results.

For the representative-agent model and a given RRA coefficient, the volatility of annual consumption growth increases by roughly $19 \%$ when the representative-agent is assumed to make annual rather than monthly decisions. This increase can be thought of as the impact of temporal aggregation on the volatility of annual consumption growth implied by the representative-agent model. Similarly, the volatility of quarterly consumption growth increases by roughly $16 \%$ when the representative-agent is assumed to make quarterly rather than monthly decisions. However, the results show a less than $5 \%$ increase in the annual consumption growth volatility when the agent's utility depends on quarterly rather than monthly consumption.

There is intuition for the lower volatility when decisions are made monthly rather than annually. The shorter decision interval allows consumption in the later part of the previous year to be more closely related to consumption in the early part of the current year. When utility depends on annual consumption, none of last year's consumption depends on this year's risky asset return while all of this year's consumption is affected. Note that this intuition for the volatility reduction does not rely on the improved opportunity set made available by more frequent decision-making. ${ }^{12}$

To summarize, temporal aggregation may have a considerable impact on low frequency consumption growth implied by the representative-agent model. Even so, recognizing that decisions are made monthly and not annually does not cause volatility to decline by enough to mirror the volatility in the data. For a RRA coefficient of 10 , reducing the decision interval from a year to a month reduces the standard deviation of annual consumption growth from 0.0348 to 0.0280 which is still more than double the empirical volatility. For monthly and quarterly consumption volatilities, the story is the same with the empirical volatility being less than half that implied by the model. These results suggest that temporal aggregation alone can not explain the magnitude of the equity premium for reasonable RRA values. ${ }^{13}$ 


\subsection{Impact of Staggered and Less Frequent Decision-making.}

Table 3 contains the results for the overlapping generation model with both decisions made infrequently. The moments are reported in Table 3 in the columns labeled $\sigma_{\mathrm{c}}$ and $\rho_{\mathrm{cz}}$. As the decision interval is increased for a given value of the RRA coefficient, the standard deviation of monthly aggregate consumption growth is decreasing. As to be expected, there is also a negative relation between the RRA coefficient and the variability of aggregate monthly consumption growth. For three specifications $(\{\gamma=8, \mathrm{~T}=12\},\{\gamma=10, \mathrm{~T}=6\},\{\gamma=10, \mathrm{~T}=12\})$, the standard deviation from the SDI model is less than the sample estimate for the U.S. economy in Table 1. This result suggests that infrequent and staggered decision-making by agents may be at least a partial cause of the lack of volatility of monthly aggregate consumption growth.

The results in Table 3 for annual consumption growth moments show that the impact of less frequent and staggered decision-making is very different from its impact on monthly moments. Increasing the decision interval from one month (the monthly decision-making representative-agent case) to one year has almost no impact on the volatility of annual consumption growth.

Turning to the correlation results in Table 3 , the correlation of aggregate consumption growth and risky asset return is declining in the decision interval at all three frequencies. For a given decision interval, the correlation at each of the frequencies is similar across RRA values. For a decision interval of a year, the correlations for all models is less than .30 for annual and monthly frequencies and less than .20 for quarterly. This finding is in sharp contrast to a infinitely-lived representative-agent model with risky asset return matched to consumption in which the correlation at the frequency of the decision interval is close to $1 .^{14}$

For each RRA coefficient, Table 3 also reports the standard deviation of aggregate consumption and its correlation with risky asset returns as fractions of their values in the $\mathrm{T}=1$ case. For any given moment, these fractions are remarkably stable across RRA values suggesting that it is the decision interval which determines the fraction. This is why the next section examines the impact of less frequent decision-making as the data frequency is varied for only one RRA value. 


\subsection{Data Frequency Relative to Decision Interval.}

As is discussed in the previous section, Table 3 documents an inability to reduce annual aggregate consumption volatility in the SDI economy relative to the $T=1$ case. This inability is likely due to decision intervals greater than a year not being considered. The evidence supporting this contention is contained in Figure 3 which reports consumption growth standard deviations for the $R R A=5$ model as the data interval $F$ is varied from 1 to 12 months by monthly increments. A comparison of the standard deviation to that for the $\mathrm{T}=1$ model standard deviations shows that less frequent decision-making causes volatility reductions for $\mathrm{F}$ less than the decision interval. When $\mathrm{F}$ equals the decision interval, there is a reduction in volatility but it is small. As $\mathrm{F}$ increases beyond $\mathrm{T}$, the standard deviation approaches that for the $\mathrm{T}=1$ case. The results for $\mathrm{T}=3$ and $\mathrm{F} \geq 8$ indicate that for $\mathrm{F}$ sufficiently large relative to the decision interval, the volatility becomes greater than in the monthly decision interval $(\mathrm{T}=1)$ case.

So why is consumption growth volatility at the decision interval frequency similar to that for the $T=1$ case while monthly volatility declines monotonically as the decision interval is increased? The reason is positive autocorrelation in monthly aggregate consumption growth induced by the staggered decision-making. This autocorrelation persists out to longer lags as the decision interval increases. ${ }^{15}$

To summarize, Figure 3 indicates that the relative frequency of the data (relative to the decision frequency) is the crucial determinant of less frequent decision-making's impact on aggregate consumption growth volatility. Further, this conclusion together with Table 3 suggest that unless a decision interval longer than a year is considered reasonable, staggered decision-making by itself is unable to deliver substantial reductions in the volatility of annual aggregate consumption growth volatility relative to the $\mathrm{T}=1$ case.

Figure 4 reports correlations for the $\mathrm{RRA}=5$ model at data intervals from 1 to 12 months in increments of a month. For each data frequency, the correlation is monotonically declining in the decision interval, a result which is consistent with the Table 3 results. However, the finer grid for the data frequency allows one to focus on the relation between correlation and data frequency for any given decision interval. For $\mathrm{T}=1$ (the representative-agent case), there is a positive relation between correlation and data frequency which is monotonic. For $\mathrm{T}>1$, there is a U-shaped relation with 
correlation highest for the lowest and highest data frequencies. Further the data frequency with the lowest correlation is decreasing in the decision interval for intervals greater than 1 month. Thus, it seems that the introduction of less frequent and staggered decision-making changes the nature of the relation between aggregate consumption and asset returns relative to the $T=1$ case.

\subsection{Impact of Staggering vs Impact of Less Frequent Decision-making: Two Decompositions.}

The representative-agent based decomposition assesses the separate effects of infrequent decision-making and staggering on low frequency moments. The effect of the staggered and annual decision-making on annual moments is decomposed from Table 2 as follows: 1) the less frequent decision-making increases the volatility of aggregate consumption growth by around 19\% (see

Section 4.1 above); and, 2) staggering reduces the volatility back to a level which is slightly less than for the $T=1$ case. Staggering causes this year's consumption to be more like last year's due to people making decisions throughout the year; this causes the volatility reduction at low frequencies.

The second decomposition which is based on moments for a chosen class would be expected to indicate smaller low frequency volatility increases due to less frequent decision-making than the first decomposition. The reason is that the variance for the chosen class is obtained by averaging over all $\mathrm{T}$ possible \{consumption interval, decision interval\} combinations while the representativeagent variance is that for the \{consumption interval, decision interval\} combination with the largest volatility. The moments are reported in Table 3 in the columns labeled $\sigma_{\mathrm{cl}}$ and $\rho_{\mathrm{clz}}$ and confirm this intuition.

This second decomposition can also be performed for the high frequency moments. For all three data frequencies reported, the chosen class's consumption growth volatility is virtually the same as the $T=1$ case irrespective of the decision interval $T$. This result suggests that none of the volatility reductions at high frequencies is due to the infrequent decision-making alone. Rather, it is the incremental effect of the staggering which causes the reductions. The implication is that the volatility reduction is due to an effect not directly analogous to the one documeneted by GrossmanLaroque for a durable good.

Mechanically, staggering's ability to reduce volatility can be explained by noting that 
variance as a metric of dispersion can vary while the mean absolute deviation remains constant. In particular, having fewer outliers whose absolute deviations from the mean are larger can cause mean absolute deviation to remain constant even though variance increases. With the chosen class, consumption growth is deterministic for (T-1) periods while in the Tth period consumption is adjusted in response to the risky asset return realizations over the previous T periods. With the SDI economy and monthly consumption growth, there is a deviation from the mean each period which is roughly $(1 / \mathrm{T})$ th of the chosen class deviation as $(1 / \mathrm{T})$ th of the population makes a decision. But while the mean absolute deviation is roughly the same, the above stated property of variance as a dispersion metric causes the chosen class's monthly consumption volatility to be much higher than for the aggregate.

Turning to the correlation of consumption growth with risky asset return, the chosen class decomposition indicates that less frequent decision-making alone causes large reductions at any frequency. For example, with $\gamma=5$, the monthly correlation drops from 0.9978 to 0.0726 going from $\mathrm{T}=1$ with aggregate consumption to $\mathrm{T}=12$ with the chosen class's consumption.

The incremental impact of the staggering is to increase the correlation but to leave the covariance unaffected. Continuing the previous paragraph's example, the monthly correlation rises to 0.2856 when staggering is introduced (aggregate consumption from the SDI model with $\mathrm{T}=12$ ). However, for this example, since the ratio of the correlation with staggering and without is equal to the inverse of the ratio for consumption volatility, it follows that the covariance of consumption

growth and risky asset return is unaffected by the introduction of staggering. And as this equality holds for any frequency, it seems that in general staggering affects the correlation not by affecting covariance but solely through its effect on consumption growth volatility.

The message of this section is that the less frequent decision-making drives the correlation reductions while the staggering causes the volatility reductions.

\subsection{Separate Impacts of Less Frequent Investment Decision-making and of Less Frequent Consumption Decision-making.}

The previous sections present results showing that less frequent and staggered decisionmaking reduces the volatility of relatively high frequency aggregate consumption growth and 
reduces its correlation with risky asset return at any frequency. The question raised by these results is whether the less frequent consumption or less frequent investment decision-making is driving these reductions.

Table 4 presents results for the overlapping generations model in which only consumption decisions are made infrequently. The results for both the volatility of aggregate consumption growth and its correlation with risky asset return are very similar to those for the model in which both decisions are made infrequently. To quantify the similarity, the moment reported in Table 4 for a given $T_{C}$ is divided by the same moment in Table 3 (both decisions made infrequently) for $T=T_{C}$. This ratio is never more than $0.06(0.16)$ away from 1 for aggregate consumption growth volatility (correlation with risky asset return).

Table 5 reports results for the converse case where only investment decisions are made infrequently. Since the consumer's problem can only be solved numerically in this case, the results are for a smaller range of decision intervals and RRA values. For a given RRA value, the results when $T_{I}$ is either 2 or 3 and $T_{C}$ is 1 are very similar to those when $T_{I}=T_{C}=1$ (the monthly decisionmaking representative-agent case). To again quantify the similarities, the table also reports the ratio of each moment to the same moment when $T_{I}=1$. This ratio is never more than 0.03 away from 1 for the volatility of aggregate consumption growth or its correlation with risky asset return.

These results indicate that the less frequent consumption decision-making is driving the reductions in consumption volatility and correlation with risky asset return observed when both decisions are made infrequently. When consumption decisions are being made infrequently, rebalancing every period rather than at the time of each consumption decision results in a problem for the individual which is of the same basic form. ${ }^{16}$ In each case, the consumer sets aside a bundle of money for consumption at the start of each decision interval, and invests the remaining wealth. The only difference is a better opportunity set available for the remaining wealth when individuals rebalance each period. The results of Tables 3-5 suggest that the smaller opportunity set which results from less frequent rebalancing has a negligible effect on both the volatility of aggregate consumption growth and its correlation with risky asset return, at least for decision intervals less than 3 months.

This finding complements Constantinides [1986] who found that the presence of proportional 
transaction costs in the asset market have a negligible effect on the required equity premium. Proportional transaction costs alone imply a state-dependant decision rule. The results in Table 5 suggest that Constantinides' conclusion continues to hold when the decision interval is not allowed to be state-dependant but is instead assumed constant. Table 5 can be interpreted as suggesting that the second order effect of proportional asset market transaction costs on the equity premium is likely to be robust to the presence of information processing costs.

Table 5 's results also suggest that the reductions in annual aggregate consumption growth volatility for the representative agent when the decision interval goes from 12 months to 1 month (see Table 2) are not due to the improved opportunity set made available by more frequent decisionmaking. ${ }^{17}$

\subsection{Less Frequent and Staggered Decision-making with a Second Risky Asset.}

Table 6 reports calibration results for the SDI model with a second risky asset added to individuals' opportunity set. The major result pertains to the percentage reduction (relative to the $\mathrm{T}=1$ model) in both the volatility of aggregate consumption and its correlation with equity return when the decision interval is increased. For any given frequency, the magnitude of this reduction depends only on the decision interval. Adding an extra risky asset or changing the RRA coefficient does not affect the percentage reduction in either the standard deviation or the correlation. So the incremental effect of less frequent and staggered decision-making on these two moments is robust to the addition of a second risky asset.

\section{$5 \quad$ The Utility Cost of Less Frequent Decisions.}

Closed form solutions exist for the infinitely-lived power consumer's problem when consumption and investment decisions are made at the same frequency. Thus, it is possible to calculate measures of the utility cost associated with less frequent decision-making. The costs reported in Table 7 are for an infinitely lived consumer with a rate of time preference of 1 . The risky and riskless asset return processes are the same as for the one risky asset calibration work discussed above.

By making decisions every $\mathrm{T}$ months, the individual enjoys a certain level of utility at the 
time of making a decision which depends on her wealth. If she made decisions every period, she could attain this level of utility with a reduced level of wealth. The reported cost is the fractional reduction in her wealth which would allow her to attain the same level of utility by making decisions every period. For all values of the RRA coefficient and any decision interval up to a year, this fractional cost is less than $1 \%$. If the decision interval is restricted to be less than six months then the fractional utility cost is always less than $0.5 \%{ }^{18}$

The apparently low utility cost associated with infrequent decision-making supports the plausibility of the argument that costly information processing, transacting and optimizing could cause individuals to make decisions less frequently. These results compliment work by Cochrane [1989], Caballero [1992] and Marshall [1993] whose evidence indicates that the utility cost of nearrational behavior is small.

\section{Concluding Remarks.}

Casual observation of human behavior suggests people decide infrequently how much to spend on consumption but are constantly deciding which products are to be consumed with the allocated money. The decision on how much to allocate to consumption depends largely on current wealth and can be a time-consuming activity; people try to behave optimally. Within a decision interval, product choices depend on relative prices, product innovation and whim and are made subject to the total within-interval consumption constraint; wealth shocks within the interval are largely irrelevant. My model captures the essence of this behavior.

Reider [1994] examines what happens when consumption services from a Grossman-Laroque durable good are only a fraction of measured consumption and the remainder is nondurables. If the nondurables consumption is being adjusted continuously, the ability of a durable good transaction cost to deliver an equity premium with respect to measured consumption is severely reduced. One of the main themes of my paper is that less frequent and unsynchronized consumption nondurables decision-making by individuals may be an important reason for the smoothness of aggregate consumption (particularly at high frequencies) and its lack of correlation with risky asset returns. Thus, the paper complements the work of Grossman and Laroque and indicates that Reider's results do not hold if nondurable consumption decisions are made infrequently. 
My model also complements Caballero's investigation of the behavior of aggregate nondurables consumption in the presence of near-rational behavior by agents. He assumes individual's use a state dependant adjustment rule with respect to nondurables consumption while I consider a model in which individuals make decisions at fixed intervals. Both models are able to explain aspects of the U.S. data which are puzzling within the frictionless market, representative agent paradigm.

Further work is needed to empirically discriminate between these two models and such efforts would seem worthwhile. In contrast to representative-agent models with decision-making every period, models with consumption decision-making frictions are able to deliver the low correlation between aggregate consumption and asset returns found in the data. Important recent work by Campbell and Cochrane [1994] considers a representative-agent model in which utility exhibits slowly moving habit. They are able to explain the equity premium and many other features of the data including return predictability. However, the one feature left unexplained is the low correlation of aggregate consumption with stock returns.

Another theme of my paper is that nonsynchroneity of decision-making has distinct effects from those of less frequent decision-making. Thus, the time series properties of consumption depend on both decision frequency and degree of synchronization across agents. For example, given a decision interval of a year, aggregate consumption is likely to behave very differently depending on whether $1 / 12$ of the population make a decision each month or $90 \%$ makes their decision in January. In particular, the nature of the seasonality in aggregate consumption would be affected.

An interesting feature of the SDI model presented in this paper is its potential to be tested using aggregate consumption data. The simple decision structure allows the marginal rate of substitution of the class determining prices each period to be expressed as a function of parameters, current and past aggregate consumption and interest rates and an initial condition. There are some difficult econometric issues involved in estimating this type of model but some preliminary work is contained in Lynch [1994].

Finally, the SDI model seems well suited for trying to explain monthly stock return behavior particularly the documented autocorrelation behavior. Such an exploration would involve calibrating an economy where prices are determined endogenously and this is work in progress. 


\section{Appendix: Solutions for the Overlapping Generations Economies}

As mentioned above, the consumer's problem in the SDI economy of Section 1.1 has a closed-form solution. Letting $\mathrm{t}^{\mathrm{i}, \ell}=[\mathrm{wL}+\ell] \mathrm{T}+\mathrm{i}$ then the solution for individual $(\mathrm{i}, \ell)$ alive at $\mathrm{t}^{\mathrm{i}, \ell}+\phi \mathrm{T}+\tau$, $\phi=0,1, \ldots, \mathrm{L}-1$ and $\tau=0,1, \ldots, \mathrm{T}-1$ is given by:

$$
E_{t^{u}, \phi T}\left[\left[y^{T}\left(t^{i, l}+\phi T\right]^{-\gamma}\left(R^{z}\left(t^{i, l}+\phi T, t^{i, l}+[\phi+1] T\right)-R^{T}\right)\right]=0\right.
$$

where: $y^{T}\left(t^{i, l}+[\phi+1] T\right)=\alpha^{i, l}\left(t^{i, l}+\phi T\right)\left(R^{z}\left(t^{i, l}+\phi T, t^{i, l}+[\phi+1] T\right)-R^{T}\right)+R^{T}$;

and,

$$
\begin{aligned}
& W^{i, l}\left(t^{i, l}+\phi T\right)=W^{i, l}\left(t^{i, l}\right) \prod_{j=1}^{\phi}\left(1-a_{j-1}^{T}\right) y^{T}\left(t^{i, l}+j T\right) \\
& \hat{c}^{i, l}\left(t^{i, l}+\phi T\right)=a_{\phi}^{T} W^{i, l}\left(t^{i, l}+\phi T\right) \\
& c^{i, l}\left(t^{i, l}+\phi T+\tau\right)=\hat{c}^{i, l}\left(t^{i, l}+\phi T\right) K_{\tau} \\
& K_{\tau}=K_{0}(\beta R)^{\tau / \gamma} \\
& \text { where: } \\
& \Omega^{T}=\left(\beta E_{t}\left[\left[y^{T}(t+T)\right]^{1-\gamma}\right]\right)^{-1 / \gamma} ; \\
& K_{0}^{-1}=\frac{1-\left(\beta^{1 / \gamma} R^{1 / \gamma-1}\right)^{T}}{1-\left(\beta^{1 / \gamma} R^{1 / \gamma-1}\right)} ; \text { and }, a_{\phi}^{T}=\frac{1-\left(\Omega^{T}\right)^{-1}}{1-\left(\Omega^{T}\right)^{-(L-\phi)}} .
\end{aligned}
$$

The solution to the consumer's problem when only the consumption decision is made less frequently (Section 1.2) is just a modification of (15) and (16). The optimal portfolio weight is given by (15) for $T=1$ and the consumption decision is characterized by (16) with $y^{T}\left(t^{\mathrm{i}, \ell}+\mathrm{j} T\right)$ replaced by $\left[y^{1}\left(t^{\mathrm{i}, \ell}+(\mathrm{j}-1) \mathrm{T}+1\right) \mathrm{y}^{1}\left(\mathrm{t}^{\mathrm{i}, \ell}+(\mathrm{j}-1) \mathrm{T}+1\right) \ldots \mathrm{y}^{\mathrm{l}}\left(\mathrm{t}^{\mathrm{i}, \ell}+\mathrm{j} T\right)\right]$ and with $\Omega^{\mathrm{T}}$ replaced by $\left(\Omega^{\mathrm{l}}\right)^{\mathrm{T}}$. The solution to the consumer's problem is of the same form as when both decisions are made infrequently except that the individual, by rebalancing her portfolio every period instead of every $\mathrm{T}$ periods has access to an improved opportunity set.

The solution to the consumer's problem in Section 1.3 with only investment decisions made less frequently can be characterized as follows. It is easy to see that for $\mathrm{j}=0,1, \ldots, \mathrm{L}-1$, the value function is of the form:

$\mathrm{V}_{\mathrm{j}, \phi}\left(\mathrm{W}^{\mathrm{i}, \ell}([\mathrm{wL}+\ell+\mathrm{j}] \mathrm{T}+\mathrm{i})\right)$ for $\phi=0$; and, $\mathrm{V}_{\mathrm{j}, \phi}\left(\mathrm{W}^{\mathrm{i}, \ell}([\mathrm{wL}+\ell+\mathrm{j}] \mathrm{T}+\mathrm{i}+\phi), \mathrm{X}^{\mathrm{i}, \ell}([\mathrm{wL}+\ell+\mathrm{j}] \mathrm{T}+\mathrm{i}+\phi)\right)$ for $\phi=1,2, \ldots, \mathrm{T}-1$.

Consequently, the individual's consumption and investment decisions can be represented:

$\alpha^{\mathrm{i}, \ell}([\mathrm{wL}+\ell+\mathrm{j}] \mathrm{T}+\mathrm{i})=\mathrm{f}_{\mathrm{j}}\left(\mathrm{W}^{\mathrm{i}, \ell}([\mathrm{wL}+\ell+\mathrm{j}] \mathrm{T}+\mathrm{i})\right)$;

$c^{i, \ell}([w L+\ell+j] T+i)=g_{j, 0}\left(W^{i, \ell}([w L+\ell+j] T+i)\right)$; and, 
$\mathrm{c}^{\mathrm{i}, \ell}([\mathrm{wL}+\ell+\mathrm{j}] \mathrm{T}+\mathrm{i}+\phi)=\mathrm{g}_{\mathrm{j}, \phi}\left(\mathrm{W}^{\mathrm{i}, \ell}([\mathrm{wL}+\ell+\mathrm{j}] \mathrm{T}+\mathrm{i}+\phi), \mathrm{X}^{\mathrm{i}, \ell}([\mathrm{wL}+\ell+\mathrm{j}] \mathrm{T}+\mathrm{i}+\phi)\right)$ for $\phi=1,2, \ldots, \mathrm{T}-1$.

It can easily be shown that $V_{j, 0}(W)$ is homogenous of degree $(1-\gamma)$ in $W, V_{j, \phi}(W, X)$ is homogenous of degree $(1-\gamma)$ in $(W, X), g_{j, 0}(W)$ is homogenous of degree 1 in $W, f_{j}(W)$ is homogenous of degree 0 in $W$ and $g_{j, \phi}(W, X)$ is homogenous of degree 1 in $(W, X)$. This is enough structure to numerically solve the consumer's problem at least when there are a finite number of states. The homogeneity implies that:

$$
\begin{array}{r}
\mathrm{V}_{\mathrm{j}, 0}(\mathrm{~W})=\mathrm{a}_{\mathrm{j}}\left[\mathrm{W}^{1-\gamma}\right] ; \mathrm{f}_{\mathrm{j}}(\mathrm{W})=\alpha_{\mathrm{j}} ; \mathrm{g}_{\mathrm{j}, 0}(\mathrm{~W})=\mathrm{b}_{\mathrm{j}, 0} \mathrm{~W} ; \text { and } \\
\mathrm{g}_{\mathrm{j}, \boldsymbol{\phi}}\left(\mathrm{W}(\mathrm{t}), \mathrm{X}(\mathrm{t})=\mathrm{h}_{\mathrm{j}, \phi}\left(\mathrm{W}(\mathrm{t}-\phi), \mathrm{R}^{\mathrm{z}}(\mathrm{t}-\phi, \mathrm{t}-\phi+1), \ldots, \mathrm{R}^{\mathrm{z}}(\mathrm{t}-1, \mathrm{t})\right)\right. \\
=\mathrm{b}_{\mathrm{j}, \phi}\left(\mathrm{R}^{\mathrm{z}}(\mathrm{t}-\phi, \mathrm{t}-\phi+1), \ldots, \mathrm{R}^{\mathrm{z}}(\mathrm{t}-1, \mathrm{t})\right) \mathrm{W}(\mathrm{t}-\phi) .
\end{array}
$$

Without loss of generality, consider the problem of the $(0,0)$ th individual for $w=0$. The problem is solved backwards by first recognizing that the last (Lth) portfolio decision at (L-1)T is to invest all wealth in the riskless asset and consume the remainder of that wealth from (L-1)T to LT1. It is straightforward to calculate $a_{L-1}, \alpha_{L-1}$ and $b_{L-1, \phi}(\cdot)=b_{L-1, \phi}$ a constant. So given $a_{j+1}$, one obtains $a_{j}, \alpha_{j}$ and $b_{j, \phi}(\cdot)$ by solving the following optimization problem for given $W_{j, 0}$ :

$$
\begin{aligned}
a_{j} W_{j, 0}^{1-\gamma}= & \max \left\{E \left[\sum_{\psi=0}^{T-1} \beta^{\psi} \frac{\left[b_{j, \psi}\left(R^{z}(j T, j T+1), \ldots, R^{z}(j t+\psi-1, j t+\psi)\right) W_{j, 0}\right]^{1-\gamma}}{1-\gamma}\right.\right. \\
& +\beta^{T} a_{j+1}\left[W_{j, T}\left(R^{z}\left(j T, j T+1, \ldots, R^{z}(j T+T-1,(j+1) T)\right)\right]^{1-\gamma} \mid W_{j, 0}\right\}
\end{aligned}
$$

s.t.

$$
\begin{aligned}
& W_{j, \phi+1}\left(R^{z}(j T, j T+1), \ldots, R^{z}(j T+\phi, j T+\phi+1)\right)=\left[W _ { j , \phi } \left(R^{z}(j T, j T+1), \ldots, R^{z}(j T+\phi-1, j T+\phi)\right.\right. \\
& \left.-\left(\alpha_{j} \prod_{\psi=1}^{\phi} R^{z}(j T+\psi-1, j T+\psi)+b_{j, \phi}\left(R^{z}(j t, j T+1), \ldots, R^{z}(j t+\phi-1, j t+\phi)\right)\right) W_{j, 0}\right] R \\
& +\left[\alpha_{j} W_{j, 0} \prod_{\psi=1}^{\phi+1} R^{z}(j T+\psi-1, j T+\psi)\right], \quad \phi=0,1, \ldots, T-1 .
\end{aligned}
$$

However, as $\mathrm{T}$ increases the number of choice variables increases exponentially such that the starting values play a crucial role in being able to find a solution. For this reason, results are only available for $\mathrm{T} \leq 3$. 


\section{Footnotes}

1.Lucas [1994] and Telmer [1993] find that the availability of a risky and riskless asset allows individuals to smooth temporary income shocks. This ability continues despite the presence of reasonable transaction costs in both asset markets and persistence in the idiosyncratic income shocks designed to match the PSID data (see Heaton and Lucas [1994]). The only way to get an equity premium of the observed magnitude is to have two-sided costs in the risky asset market and onesided costs borne by the borrower of the riskless asset.

2.Though addressing a different set of issues, my model is in the spirit of Rotemberg [1984] and Grossman and Weiss [1983] who examine the effects of monetary policy using a model in which individuals visit the bank infrequently and in a staggered fashion.

3.Other papers which consider the effects of temporal aggregation include Christiano, Eichenbaum and Marshall [1991], Ermini [1989a and b] and Heaton [1993].

4.The correlation increases due to the reduction in consumption growth volatility.

5.See Caballero [1992], Cochrane [1989] and Marshall [1993] who present utility cost calculations for various forms of near rationality.

6.Note that formulas for growth in aggregate consumption and growth in the consumption of a chosen class depend on the data frequency $1 / \mathrm{F}$, parameters $g$ and $\gamma$, the riskless rate $R$, the assumed distribution for $\mathrm{R}^{\mathrm{z}}$ and the path of $\mathrm{R}^{\mathrm{z}}$ but not on the assumed value of $\mathrm{W}(0)$.

7.Monthly, quarterly and annual sample moments are calculated using 395, 393 and 384 observations respectively.

8.Several simulations are repeated to check the reliability of the results. The estimates for both the standard deviation of aggregate consumption and its correlation with risky asset return are virtually identical whenever a simulation is repeated.

9.Given knowledge of the class, its consumption growth is not stationary. Rather this variable's distribution for any given $t$ depends on the timing of that consumption interval relative to the class's decision intervals. However, by assuming that the chosen class is not known and that each class is equally likely to be chosen, the class's consumption growth can be treated as a stationary random 
variable.

10.This moment calculation can be contrasted with the representative-agent moments where only every Tth observation is used to ensure that each measurement interval starts and ends with a decision by the chosen class.

11.These results are available from the author on request.

12.The results of the overlapping generations model in which only consumption decisions are made infrequently are discussed in Section 4.5 and suggest the improved opportunity set obtained from more frequent portfolio rebalancing has a negligible affect on consumption volatility.

13.However, the model does not consider what happens if the agent makes decisions continuously. 14.Correlations of 1 are not observed in Table 2 mainly because the return interval does not match the consumption number. Rather the adopted timing convention reflects the way returns and consumption are matched when empirical data series are used.

15.Perhaps the use of a utility specification that takes account of durability in the consumption good can alleviate this positive autocorrelation (see Heaton [1993] for an example of durability having this affect on aggregate consumption which is time averaged at high frequencies). However, the presence of durability will cause the volatility of high frequency consumption growth to increase. 16. See Section 1.2 for details.

17.An explanation that does not depend on an improved opportunity set is discussed in Section 4.1. 18.Utility cost as a function of RRA is of the opposite sign to that found by Caballero [1992]. He obtains a positive relation because wealth shocks in his model are invariant to RRA while the portfolio decision in my model implies that portfolio return volatility is decreasing in RRA. 


\section{References}

Caballero, R., 1992, Near-rationality, heterogeneity and aggregate consumption, NBER Working Paper \#4035.

Caballero, R., 1993, Durable goods: An explanation for their slow adjustment, Journal of Political Economy, 101, 351-384.

Campbell, J. and J. Cochrane, 1994, By force of habit: A consumption-based explanation of aggregate stock market behavior, Working Paper, August.

Christiano, L., M. Eichenbaum and D. Marshall, 1991, The Permanent Income Hypothesis Revisited, Econometrica, 59(2), 397-423.

Cochrane, J., 1989, The sensitivity of tests of the intertemporal allocation of consumption to nearrational alternatives, American Economic Review, 79, 319-337.

Cochrane, J. and L. Hansen, 1992, Asset pricing explorations for macroeconomics, NBER Macroeconomics Annual 1992. Cambridge, MA: MIT Press.

Constantinides, G., 1986, Capital market equilibrium with transaction costs, Journal of Political Economy, 94, No.4.

Constantinides, G., 1990, Habit formation: A Resolution of the equity premium puzzle, Journal of Political Economy, 98, 519-543.

Duffie, D. and T. Sun, 1990, Transaction costs and portfolio choice in a discrete-continuous-time setting, Journal of Economic Dynamics and Control, 14, 35-51.

Ermini, L., 1989a, Excessive sensitivity of consumption and postponed revision of the optimum plans, Journal of Macroeconomics, 11, No.3, 409-422.

Ermini, L., 1989b, Some new evidence on the timing of consumption decisions and on their generating process, Review of Economics and Statistics, 71, 643-650.

Fama, E. and G. Schwert, 1977, Asset returns and inflation, Journal of Financial Economics, 5, 115-146.

Ferson, W. and C. Harvey, 1992, Seasonality and consumption-based asset pricing, Journal of Finance, 67, No.2, 511-552.

Grossman, S. and G. Laroque, 1990, Asset pricing and optimal portfolio choice in the presence of illiquid durable consumption goods, Econometrica, 58, 25-51. 
Grossman, S. and L. Weiss, 1983, A transaction based model of the monetary transmission mechanism, American Economic Review, 73, 871-880.

Hansen, L. and K. Singleton, 1982, Generalized instrumental variables estimation of nonlinear rational expectations models, Econometrica, 50, 1269-1285.

Hansen, L. and K. Singleton, 1983, Stochastic consumption, risk aversion, and the temporal behavior of asset returns, Journal of Political Economy, 91, 249-265.

He, H. and D. Modest, 1991, Market frictions and consumption-based asset pricing, Working Paper, University of California at Berkeley.

Heaton, J., 1993, The interaction of time-nonseparable preferences and time aggregation, Econometrica, 61, No.2, 353-385.

Heaton, J. and D. Lucas, 1992, The effects of Incomplete insurance markets and trading costs in a consumption-based asset pricing model, Journal of Economic Dynamics and Control, $16,601-620$.

Heaton, J. and D. Lucas, 1994, Evaluating the effects of incomplete markets on risk sharing and asset pricing, Working Paper, MIT.

Ingersoll, J. Jr., 1987, Theory of Financial Decision Making. Savage, Maryland: Rowman and Littlefield Publishers, Inc.

Lucas, D., 1994, Asset pricing with undiversifiable income risk and short sales constraints: Deepening the equity premium puzzle, forthcoming Journal of Monetary Economics.

Luttmer, E., 1992, Asset pricing in economies with frictions, Working Paper, Department of Economics, University of Chicago.

Lynch, A.W., 1994, Unsynchronized and Infrequent Decision-making by Individuals: Some Empirical Evidence, Working Paper, New York University.

Mankiw, N., 1986, The equity premium puzzle and the concentration of aggregate shocks, Journal of Financial Economics, 17, 211-219.

Marshall, D., 1993, Asset Return Volatility with Extremely Small Costs of Consumption Adjustment, Working Paper, Northwestern University.

Mehra, R. and E. Prescott, 1985, The equity premium: A puzzle, Journal of Monetary Economics, $15,145-161$. 
Reider, R., 1994, Can Transaction Costs on Durables Explain High Estimates of Risk Aversion, Working Paper, The Wharton School, University of Pennsylvania.

Rotemberg, J., 1984, A monetary equilibrium model with transaction costs, Journal of Political Economy, 92, 40-58.

Telmer, C., 1993, Asset pricing puzzles and incomplete markets, Journal of Finance, 48, 18031832. 


\section{Table 1}

Sample moments for the following U.S. data series over the period $1 / 59$ to $12 / 91$ :

$\mathrm{R}^{\mathrm{z}}\left(\mathrm{t}_{1}, \mathrm{t}_{2}\right)$ denotes the real discretely compounded return on a value weighted index of NYSE stocks from the end of month $t_{1}$ until the end of month $t_{2}$;

$\bar{c}(t+1)$ denotes aggregate percapita real consumption of nondurables and services from month $\mathrm{t}+1$ to month $\mathrm{t}+\mathrm{F}$; and

$\mathrm{R}(\mathrm{t})$ is the month-t return on the shortest term U.S. treasury bill having not less than one month to maturity.

Data sources are described in Section 2.1.

Monthly Consumption Data for 1/59 to 12/91

\begin{tabular}{llll}
\hline \hline Sample Moment & \multicolumn{3}{c}{$\mathrm{F}$} \\
\cline { 2 - 4 } & 1 & 3 & 12 \\
\hline \hline $\operatorname{av}\left[\mathrm{R}^{\mathrm{z}}(\mathrm{t}, \mathrm{t}+\mathrm{F})\right]$ & 1.005343 & 1.01552 & 1.06512 \\
$\operatorname{std}\left[\mathrm{R}^{\mathrm{z}}(\mathrm{t}, \mathrm{t}+\mathrm{F})\right]$ & 0.04385 & 0.07812 & 0.1610 \\
$\operatorname{av}\left[\overline{\mathrm{c}}_{\mathrm{F}}(\mathrm{t}) / \mathrm{c}_{\mathrm{F}}(\mathrm{t}-\mathrm{F})\right]$ & 1.001628 & 1.004870 & 1.02026 \\
$\operatorname{std}\left[\overline{\mathrm{c}}_{\mathrm{F}}(\mathrm{t}) / \mathrm{c}_{\mathrm{F}}(\mathrm{t}-\mathrm{F})\right]$ & 0.004078 & 0.004854 & 0.01237 \\
$\rho\left[\mathrm{R}^{\mathrm{z}}(\mathrm{t}, \mathrm{t}+\mathrm{F}), \overline{\mathrm{c}}_{\mathrm{F}}(\mathrm{t}+1) / \mathrm{c}_{\mathrm{F}}(\mathrm{t}+1-\mathrm{F})\right]$ & 0.1289 & 0.1605 & -0.0315 \\
$\operatorname{av}[\mathrm{R}(\mathrm{t})]$ & 1.001087 & & \\
\hline \hline
\end{tabular}




\section{Table 2}

Moments for the consumption of one decision-making class in an overlapping generation, twenty year life model in which power utility individuals make consumption and investment decisions every $\mathrm{T}$ periods and there is staggered decision making across individuals. For each data frequency, a consumption observation for the class can be calculated each period but only every Tth observation is used to calculate moments. Each usable observation is the class's consumption over an interval that starts with a decision by the class. Moments can be treated as being for a representative-agent economy where the agent makes decisions every $\mathrm{T}$ periods. Further detail on how these moments are calculated is in Section 3.1.

Regarding the economy simulated, newborn's initial wealth is assumed to growth at $0.2 \%$ so that this month's newborn have initial wealth which is 1.002 times the initial wealth of last month's newborn. The riskfree rate and parameters of the Binomial process for the risky asset are chosen to match the sample moments for the U.S. economy over the period 1/59-12/91 (see Table 1). A rate of time preference of 1 is used. Further details are in Sections 1.1 and 2.2.

Results are based on 5 simulations of 10000 observations. $\gamma$ is the RRA coefficient and $1 / F$ is the data frequency. Further, $R^{2}(t, t+F)$ is risky asset return from $t$ to $(t+F)$ while $\bar{c}_{\mathrm{F}}(t+1)$ is the sum of consumption from time $(\mathrm{t}+1)$ to time $(\mathrm{t}+\mathrm{F})$ of the class making a decision at $(\mathrm{t}+1)$. Let $\sigma_{\mathrm{c}}(\gamma, \mathrm{T}, \mathrm{T}, \mathrm{F})$ denote $\sigma\left[\overline{\mathbf{c}}_{\mathrm{F}}^{\prime}(\mathrm{t}) / \mathrm{c}_{\mathrm{F}}{ }^{\prime}(\mathrm{t}-\mathrm{F})\right]$ and $\rho_{\mathrm{c}^{\prime} \mathrm{z}}(\gamma, \mathrm{T}, \mathrm{T}, \mathrm{F})$ denote $\rho\left[\mathrm{R}^{\mathrm{z}}(\mathrm{t}, \mathrm{t}+\mathrm{F}),\left\{\overline{\mathrm{c}}_{\mathrm{F}}^{\prime}(\mathrm{t}+1) / \overline{\mathrm{c}}_{\mathrm{F}}^{\prime}(\mathrm{t}+1-\mathrm{F})\right\}\right]$, both for the SDI economy with a decision interval of $\mathrm{T}$. 


\section{Table 2 cont}

Overlapping Generation 20 Year Life Model ( $\left.L T=240 ; g=1.002 ; T_{I}=T_{C}=T_{2} 1\right)$ : Moments for the Consumption of One Class using every Tth Observation

\begin{tabular}{|c|c|c|c|c|c|c|}
\hline \multicolumn{3}{|c|}{ Parameters } & \multicolumn{2}{|c|}{ Moments } & \multicolumn{2}{|c|}{$\mathrm{x}(\gamma, 1,1, \mathrm{~F}) / \mathrm{x}(\gamma, \mathrm{T}, \mathrm{T}, \mathrm{F})$} \\
\hline$\gamma$ & $\mathrm{T}$ & $\mathrm{F}$ & $\sigma_{\mathrm{c}^{\prime}}(\gamma, \mathrm{T}, \mathrm{T}, \mathrm{F})$ & $\rho_{\mathrm{c}^{\prime} z}(\gamma, \mathrm{T}, \mathrm{T}, \mathrm{F})$ & $\mathrm{X}=\boldsymbol{\sigma}_{\mathrm{c}^{\prime}}$ & $\mathrm{x}=\rho_{\mathrm{c}^{\prime} \mathrm{z}}$ \\
\hline \multirow[t]{6}{*}{5} & 1 & 1 & 0.01946 & 0.9978 & 1.0000 & 1.0000 \\
\hline & & 3 & 0.02806 & 0.7891 & 1.0000 & 1.0000 \\
\hline & & 12 & 0.05591 & 0.6554 & 1.0000 & 1.0000 \\
\hline & 3 & 3 & 0.03373 & 0.3334 & 0.8317 & 2.3669 \\
\hline & & 12 & 0.05777 & 0.5541 & 0.9677 & 1.1827 \\
\hline & 12 & 12 & 0.07076 & 0.0531 & 0.7902 & 12.3494 \\
\hline \multirow[t]{6}{*}{8} & 1 & 1 & 0.01216 & 0.9979 & 1.0000 & 1.0000 \\
\hline & & 3 & 0.01767 & 0.7905 & 1.0000 & 1.0000 \\
\hline & & 12 & 0.03480 & 0.6533 & 1.0000 & 1.0000 \\
\hline & 3 & 3 & 0.02120 & 0.3339 & 0.8332 & 2.3675 \\
\hline & & 12 & 0.03559 & 0.5471 & 0.9780 & 1.1941 \\
\hline & 12 & 12 & 0.04323 & 0.0611 & 0.8051 & 10.7004 \\
\hline \multirow[t]{6}{*}{10} & 1 & 1 & 0.00973 & 0.9975 & 1.0000 & 1.0000 \\
\hline & & 3 & 0.01414 & 0.7893 & 1.0000 & 1.0000 \\
\hline & & 12 & 0.02797 & 0.6530 & 1.0000 & 1.0000 \\
\hline & 3 & 3 & 0.01697 & 0.3351 & 0.8333 & 2.3552 \\
\hline & & 12 & 0.02885 & 0.5536 & 0.9693 & 1.1795 \\
\hline & 12 & 12 & 0.03480 & 0.0819 & 0.8037 & 7.9690 \\
\hline
\end{tabular}




\section{Table 3}

Moments for aggregate consumption and the consumption of one decision-making class in an overlapping generation, twenty year life model in which power utility individuals make consumption and investment decisions every $\mathrm{T}$ periods and there is staggered decision making across individuals. For a given data frequency, a consumption observation for the aggregate and the class can be calculated each period; every observation is used to calculate moments. Further detail on how these moments are calculated is in Section 3.4.

Regarding the economy simulated, newborn's initial wealth is assumed to growth at $0.2 \%$ so that this month's newborn have initial wealth which is 1.002 times the initial wealth of last month's newborn. The riskfree rate and parameters of the Binomial process for the risky asset are chosen to match the sample moments for the U.S. economy over the period 1/59-12/91 (see Table 1). A rate of time preference of 1 is used. Further details are in Sections 1.1 and 2.2.

Results are based on 5 simulations of 10000 observations. $\gamma$ is the RRA coefficient and $1 / F$ is the data frequency. Further, $R^{z}(t, t+F)$ is risky asset return from $t$ to $(t+F)$ while $\bar{c}_{F}(t+1)$ is the sum of aggregate consumption from time $(\mathrm{t}+1)$ to time $(\mathrm{t}+\mathrm{F})$ and $\overline{\mathrm{c}}_{\mathrm{F}}{ }^{1}(\mathrm{t}+1)$ is the sum of consumption from time $(\mathrm{t}+1)$ to time $(\mathrm{t}+\mathrm{F})$ of the chosen class. Let $\sigma_{\mathrm{c}}(\gamma, \mathrm{T}, \mathrm{T}, \mathrm{F})$ denote $\sigma\left[\overline{\mathrm{c}}_{\mathrm{F}}(\mathrm{t}) / \overline{\mathrm{c}}_{\mathrm{F}}(\mathrm{t}-\mathrm{F})\right], \rho_{\mathrm{cz}}(\gamma, \mathrm{T}, \mathrm{T}, \mathrm{F})$ denote $\rho\left[\mathrm{R}^{\mathrm{z}}(\mathrm{t}, \mathrm{t}+\mathrm{F}),\left\{\overline{\mathrm{c}}_{\mathrm{F}}(\mathrm{t}+1) / \overline{\mathrm{c}}_{\mathrm{F}}(\mathrm{t}+1-\mathrm{F})\right\}\right], \sigma_{\mathrm{c} 1}(\gamma, \mathrm{T}, \mathrm{T}, \mathrm{F})$ denote $\sigma\left[\overline{\mathrm{c}}_{\mathrm{F}}{ }^{1}(\mathrm{t}) / \overline{\mathrm{c}}_{\mathrm{F}}{ }^{1}(\mathrm{t}-\mathrm{F})\right]$ and $\rho_{\mathrm{clz}}(\gamma, \mathrm{T}, \mathrm{T}, \mathrm{F})$ denote $\rho\left[\mathrm{R}^{\mathrm{z}}(\mathrm{t}, \mathrm{t}+\mathrm{F}),\left\{\overline{\mathrm{c}}_{\mathrm{F}}{ }^{1}(\mathrm{t}+1) / \mathrm{c}_{\mathrm{F}}{ }^{1}(\mathrm{t}+1-\mathrm{F})\right\}\right]$, all for the SDI economy with a decision interval of $\mathrm{T}$.

Overlapping Generation 20 Year Life Model ( $\left.L T=240 ; g=1.002 ; T_{I}=T_{C}=T_{2} 1\right)$ : Moments for Aggregate Consumption and the Consumption of One Class

\begin{tabular}{|c|c|c|c|c|c|c|c|c|c|c|}
\hline \multicolumn{3}{|c|}{ Parameters } & \multicolumn{4}{|c|}{ Moments $\mathrm{y}(\gamma, \mathrm{T}, \mathrm{T}, \mathrm{F})$} & \multicolumn{4}{|c|}{$\mathrm{x}(\gamma, \mathrm{T}, \mathrm{T}, \mathrm{F}) / \mathrm{x}(\gamma, 1,1, \mathrm{~F})$} \\
\hline$\gamma$ & $\mathrm{T}$ & $\mathrm{F}$ & $y=\sigma_{c}$ & $\mathrm{y}=\boldsymbol{\sigma}_{\mathrm{c} 1}$ & $y=\rho_{c z}$ & $y=\rho_{c 1 z}$ & $\mathrm{x}=\sigma_{\mathrm{c}}$ & $\mathrm{x}=\mathrm{\sigma}_{\mathrm{cl}}$ & $\mathrm{x}=\rho_{\mathrm{cz}}$ & $\mathrm{x}=\rho_{\mathrm{clz}}$ \\
\hline 5 & 1 & $\begin{array}{r}1 \\
3 \\
12 \\
\end{array}$ & $\begin{array}{l}0.0195 \\
0.0281 \\
0.0559\end{array}$ & $\begin{array}{l}0.0195 \\
0.0281 \\
0.0559 \\
\end{array}$ & $\begin{array}{l}0.9978 \\
0.7891 \\
0.6554 \\
\end{array}$ & & $\begin{array}{l}1.000 \\
1.000 \\
1.000 \\
\end{array}$ & $\begin{array}{l}1.000 \\
1.000 \\
1.000 \\
\end{array}$ & $\begin{array}{l}1.000 \\
1.000 \\
1.000\end{array}$ & $\begin{array}{l}1.000 \\
1.000 \\
1.000\end{array}$ \\
\hline & 3 & $\begin{array}{r}1 \\
3 \\
12\end{array}$ & $\begin{array}{l}0.0112 \\
0.0258 \\
0.0566\end{array}$ & $\begin{array}{l}0.0197 \\
0.0283 \\
0.0570\end{array}$ & $\begin{array}{l}0.5733 \\
0.4861 \\
0.5698\end{array}$ & & $\begin{array}{l}0.577 \\
0.919 \\
1.013\end{array}$ & $\begin{array}{l}1.010 \\
1.010 \\
1.019\end{array}$ & $\begin{array}{l}0.575 \\
0.616 \\
0.869\end{array}$ & $\begin{array}{l}0.325 \\
0.561 \\
0.862\end{array}$ \\
\hline & 6 & $\begin{array}{r}1 \\
3 \\
12\end{array}$ & $\begin{array}{l}0.0079 \\
0.0210 \\
0.0535\end{array}$ & $\begin{array}{l}0.0200 \\
0.0285 \\
0.0551\end{array}$ & & $\begin{array}{l}0.1568 \\
0.2068 \\
0.4140 \\
\end{array}$ & $\begin{array}{l}0.404 \\
0.747 \\
0.958 \\
\end{array}$ & $\begin{array}{l}1.029 \\
1.018 \\
0.986 \\
\end{array}$ & $\begin{array}{l}0.404 \\
0.360 \\
0.658 \\
\end{array}$ & $\begin{array}{l}0.157 \\
0.262 \\
0.632 \\
\end{array}$ \\
\hline & 12 & $\begin{array}{r}1 \\
3 \\
12\end{array}$ & $\begin{array}{l}0.0056 \\
0.0161 \\
0.0514\end{array}$ & $\begin{array}{l}0.0214 \\
0.0305 \\
0.0573\end{array}$ & $\begin{array}{l}0.2856 \\
0.1962 \\
0.2723\end{array}$ & $\begin{array}{l}0.0726 \\
0.1011 \\
0.2319\end{array}$ & $\begin{array}{l}0.290 \\
0.573 \\
0.920\end{array}$ & $\begin{array}{l}1.100 \\
1.085 \\
1.026 \\
\end{array}$ & $\begin{array}{l}0.286 \\
0.249 \\
0.416 \\
\end{array}$ & $\begin{array}{l}0.073 \\
0.128 \\
0.354 \\
\end{array}$ \\
\hline
\end{tabular}


Table 3 cont

Overlapping Generation 20 Year Life Model $\left(L T=240 ; g=1.002 ; T_{I}=T_{C}=T_{z} 1\right)$ : Moments for Aggregate Consumption and the Consumption of One Class

\begin{tabular}{|c|c|c|c|c|c|c|c|c|c|c|}
\hline \multicolumn{3}{|c|}{ Parameters } & \multicolumn{4}{|c|}{ Moments $\mathrm{y}(\gamma, \mathrm{T}, \mathrm{T}, \mathrm{F})$} & \multicolumn{4}{|c|}{$\mathrm{x}(\gamma, \mathrm{T}, \mathrm{T}, \mathrm{F}) / \mathrm{x}(\gamma, 1,1, \mathrm{~F})$} \\
\hline$\underline{\gamma}$ & $\mathrm{T}$ & $\mathrm{F}$ & $\mathrm{y}=\sigma_{\mathrm{c}}$ & $\mathrm{y}=\sigma_{\mathrm{cl}}$ & $\mathrm{y}=\rho_{\mathrm{cz}}$ & $y=\rho_{\mathrm{clz}}$ & $\mathrm{x}=\mathrm{o}_{\mathrm{c}}$ & $\mathrm{X}=\mathrm{\sigma}_{\mathrm{c} 1}$ & $\mathrm{x}=\rho_{\mathrm{cz}}$ & $\mathrm{x}=\rho_{\mathrm{clz}}$ \\
\hline \multirow[t]{12}{*}{8} & 1 & 1 & 0.0122 & 0.0122 & 0.9979 & 0.9979 & 1.000 & 1.000 & 1.000 & 1.000 \\
\hline & & 3 & 0.0177 & 0.0177 & 0.7905 & 0.7905 & 1.000 & 1.000 & 1.000 & 1.000 \\
\hline & & 12 & 0.0348 & 0.0348 & 0.6533 & 0.6533 & 1.000 & 1.000 & 1.000 & 1.000 \\
\hline & 3 & 1 & 0.0070 & 0.0125 & 0.5779 & 0.3249 & 0.579 & 1.031 & 0.579 & 0.326 \\
\hline & & 3 & 0.0162 & 0.0178 & 0.4876 & 0.4428 & 0.915 & 1.008 & 0.617 & 0.560 \\
\hline & & 12 & 0.0349 & 0.0351 & 0.5592 & 0.5561 & 1.002 & 1.008 & 0.856 & 0.851 \\
\hline & 6 & 1 & 0.0049 & 0.0130 & 0.4024 & 0.1536 & 0.406 & 1.068 & 0.403 & 0.154 \\
\hline & & 3 & 0.0132 & 0.0181 & 0.2891 & 0.2110 & 0.745 & 1.026 & 0.366 & 0.267 \\
\hline & & 12 & 0.0337 & 0.0346 & 0.4368 & 0.4263 & 0.967 & 0.994 & 0.669 & 0.652 \\
\hline & 12 & 1 & 0.0035 & 0.0141 & 0.2844 & 0.0735 & 0.286 & 1.155 & 0.285 & 0.074 \\
\hline & & 3 & 0.0099 & 0.0196 & 0.1901 & 0.0928 & 0.560 & 1.112 & 0.241 & 0.117 \\
\hline & & 12 & 0.0315 & 0.0351 & 0.2663 & 0.2355 & 0.904 & 1.008 & 0.408 & 0.360 \\
\hline \multirow[t]{12}{*}{10} & 1 & 1 & 0.0097 & 0.0097 & 0.9975 & 0.9975 & 1.000 & 1.000 & 1.000 & 1.000 \\
\hline & & 3 & 0.0141 & 0.0141 & 0.7893 & 0.7893 & 1.000 & 1.000 & 1.000 & 1.000 \\
\hline & & 12 & 0.0280 & 0.0280 & 0.6530 & 0.6530 & 1.000 & 1.000 & 1.000 & 1.000 \\
\hline & 3 & 1 & 0.0056 & 0.0102 & 0.5737 & 0.3197 & 0.579 & 1.046 & 0.575 & 0.321 \\
\hline & & 3 & 0.0129 & 0.0143 & 0.4893 & 0.4464 & 0.915 & 1.009 & 0.620 & 0.566 \\
\hline & & 12 & 0.0283 & 0.0285 & 0.5667 & 0.5620 & 1.012 & 1.018 & 0.868 & 0.861 \\
\hline & 6 & 1 & 0.0039 & 0.0107 & 0.4053 & 0.1484 & 0.406 & 1.095 & 0.406 & 0.149 \\
\hline & & 3 & 0.0105 & 0.0146 & 0.2918 & 0.2131 & 0.743 & 1.031 & 0.370 & 0.270 \\
\hline & & 12 & 0.0269 & 0.0277 & 0.4390 & 0.4266 & 0.963 & 0.990 & 0.672 & 0.653 \\
\hline & 12 & 1 & 0.0028 & 0.0119 & 0.2849 & 0.0749 & 0.291 & 1.228 & 0.286 & 0.075 \\
\hline & & 3 & 0.0081 & 0.0165 & 0.1989 & 0.1042 & 0.570 & 1.166 & 0.252 & 0.132 \\
\hline & & 12 & 0.0258 & 0.0283 & 0.2848 & 0.2555 & 0.923 & 1.013 & 0.436 & 0.391 \\
\hline
\end{tabular}




\section{Table 4}

Moments for aggregate consumption in an overlapping generation, twenty year life model in which power utility individuals make consumption decisions every $T_{C}$ periods but rebalance their portfolios every period. For a given data frequency, a consumption observation for the aggregate can be calculated each period; every observation is used to calculate moments. Further detail on how these moments are calculated is in Section 3.4.

Regarding the economy simulated, newborn's initial wealth is assumed to growth at $0.2 \%$ so that this month's newborn have initial wealth which is 1.002 times the initial wealth of last month's newborn. The riskfree rate and parameters of the Binomial process for the risky asset are chosen to match the sample moments for the U.S. economy over the period 1/59-12/91 (see Table 1). A rate of time preference of 1 is used. Further details are in Sections 1.2 and 2.2.

Results are based on 5 simulations of 10000 observations. $\gamma$ is the RRA coefficient and $1 / F$ is the data frequency. Further, $R^{z}(t, t+F)$ is risky asset return from $t$ to $(t+F)$ while $\bar{c}_{F}(t+1)$ is the sum of aggregate consumption from time $(\mathrm{t}+1)$ to time $(\mathrm{t}+\mathrm{F})$ and $\overline{\mathrm{c}}_{\mathrm{F}}{ }^{1}(\mathrm{t}+1)$ is the sum of consumption from time $(\mathrm{t}+1)$ to time $(\mathrm{t}+\mathrm{F})$ of the chosen class. Let $\sigma_{\mathrm{c}}\left(\gamma, \mathrm{T}_{\mathrm{C}}, 1, \mathrm{~F}\right)$ denote $\sigma\left[\overline{\mathrm{c}}_{\mathrm{F}}(\mathrm{t}) / \mathrm{c}_{\mathrm{F}}(\mathrm{t}-\mathrm{F})\right]$ and $\rho_{c z}\left(\gamma, T_{C}, 1, F\right)$ denote $\rho\left[R^{z}(t, t+F),\left\{\bar{c}_{F}(t+1) / \bar{c}_{F}(t+1-F)\right\}\right]$, all for the economy with a consumption decision interval of $\mathrm{T}_{\mathrm{C}}$ and portfolio rebalancing every period.

Overlapping Generation 20 Year Life Model $\left(L T=240 ; g=1.002 ; T_{I}=1, T_{C^{2}}\right)$ : Moments for Aggregate Consumption

\begin{tabular}{|c|c|c|c|c|c|c|}
\hline \multicolumn{3}{|c|}{ Parameters } & \multicolumn{2}{|c|}{ Moments $y\left(\gamma, T_{C}, 1, F\right)$} & \multicolumn{2}{|c|}{$\mathrm{x}\left(\gamma, \mathrm{T}_{\mathrm{C}}, 1, \mathrm{~F}\right) / \mathrm{x}\left(\gamma, \mathrm{T}_{\mathrm{C}}, \mathrm{T}_{\mathrm{C}}, \mathrm{F}\right)$} \\
\hline$\gamma$ & $\mathrm{T}_{\mathrm{C}}$ & $\mathrm{F}$ & $\mathrm{y}=\boldsymbol{\sigma}_{\mathrm{c}}$ & $y=\rho_{c z}$ & $\mathrm{x}=\mathrm{\sigma}_{\mathrm{c}}$ & $\mathrm{x}=\rho_{\mathrm{cz}}$ \\
\hline \multirow[t]{12}{*}{5} & 1 & 1 & 0.0195 & 0.9978 & 1.000 & 1.000 \\
\hline & & 3 & 0.0281 & 0.7891 & 1.000 & 1.000 \\
\hline & & 12 & 0.0559 & 0.6554 & 1.000 & 1.000 \\
\hline & 3 & 1 & 0.0112 & 0.5780 & 1.000 & 1.008 \\
\hline & & 3 & 0.0259 & 0.4917 & 1.004 & 1.011 \\
\hline & & 12 & 0.0567 & 0.5659 & 1.001 & 0.993 \\
\hline & 6 & 1 & 0.0078 & 0.4054 & 0.993 & 1.006 \\
\hline & & 3 & 0.0208 & 0.2944 & 0.995 & 1.036 \\
\hline & & 12 & 0.0545 & 0.4573 & 1.018 & 1.061 \\
\hline & 12 & 1 & 0.0055 & 0.2840 & 0.970 & 0.995 \\
\hline & & 3 & 0.0156 & 0.1905 & 0.968 & 0.971 \\
\hline & & 12 & 0.0494 & 0.2654 & 0.960 & 0.975 \\
\hline
\end{tabular}




\section{Table 4 cont}

Overlapping Generation 20 Year Life Model (LT=240; $\left.g=1.002 ; T_{I}=1, T_{C} \geq 1\right)$ : Moments for Aggregate Consumption

\begin{tabular}{|c|c|c|c|c|c|c|}
\hline \multicolumn{3}{|c|}{ Parameters } & \multicolumn{2}{|c|}{ Moments $\mathrm{y}\left(\gamma, \mathrm{T}_{\mathrm{C}}, 1, \mathrm{~F}\right)$} & \multicolumn{2}{|c|}{$\mathrm{x}\left(\gamma, \mathrm{T}_{\mathrm{C}}, 1, \mathrm{~F}\right) / \mathrm{x}\left(\gamma, \mathrm{T}_{\mathrm{C}}, \mathrm{T}_{\mathrm{C}}, \mathrm{F}\right)$} \\
\hline$\gamma$ & $\mathrm{T}_{\mathrm{C}}$ & $\mathrm{F}$ & $\mathrm{y}=\sigma_{\mathrm{c}}$ & $y=\rho_{c z}$ & $\mathbf{x}=\boldsymbol{\sigma}_{\mathrm{c}}$ & $\mathrm{x}=\rho_{\mathrm{cz}}$ \\
\hline \multirow[t]{12}{*}{8} & 1 & 1 & 0.0122 & 0.9979 & 1.000 & 1.000 \\
\hline & & 3 & 0.0177 & 0.7905 & 1.000 & 1.000 \\
\hline & & 12 & 0.0348 & 0.6533 & 1.000 & 1.000 \\
\hline & 3 & 1 & 0.0070 & 0.5744 & 0.990 & 0.994 \\
\hline & & 3 & 0.0160 & 0.4817 & 0.987 & 0.988 \\
\hline & & 12 & 0.0343 & 0.5501 & 0.983 & 0.984 \\
\hline & 6 & 1 & 0.0049 & 0.4063 & 0.995 & 1.010 \\
\hline & & 3 & 0.0131 & 0.2910 & 0.996 & 1.007 \\
\hline & & 12 & 0.0336 & 0.4370 & 0.998 & 1.000 \\
\hline & 12 & 1 & 0.0034 & 0.2881 & 0.988 & 1.013 \\
\hline & & 3 & 0.0098 & 0.2009 & 0.990 & 1.057 \\
\hline & & 12 & 0.0315 & 0.2923 & 1.002 & 1.097 \\
\hline \multirow[t]{12}{*}{10} & 1 & 1 & 0.0097 & 0.9975 & 1.000 & 1.000 \\
\hline & & 3 & 0.0141 & 0.7893 & 1.000 & 1.000 \\
\hline & & 12 & 0.0280 & 0.6530 & 1.000 & 1.000 \\
\hline & 3 & 1 & 0.0056 & 0.5720 & 0.987 & 0.997 \\
\hline & & 3 & 0.0127 & 0.4810 & 0.982 & 0.983 \\
\hline & & 12 & 0.0276 & 0.5643 & 0.985 & 0.864 \\
\hline & 6 & 1 & 0.0039 & 0.4048 & 0.991 & 0.999 \\
\hline & & 3 & 0.0104 & 0.2894 & 0.992 & 0.992 \\
\hline & & 12 & 0.0268 & 0.4425 & 0.993 & 1.008 \\
\hline & 12 & 1 & 0.0027 & 0.2814 & 0.955 & 0.988 \\
\hline & & 3 & 0.0077 & 0.1847 & 0.953 & 0.929 \\
\hline & & 12 & 0.0243 & 0.2597 & 0.942 & 0.912 \\
\hline
\end{tabular}




\section{Table 5}

Moments for aggregate consumption in an overlapping generation, twenty year life model in which power utility individuals make consumption decisions every period but rebalance their portfolios every $T_{I}$ periods. For a given data frequency, a consumption observation for the aggregate can be calculated each period; every observation is used to calculate moments. Further detail on how these moments are calculated is in Section 3.4.

Regarding the economy simulated, newborn's initial wealth is assumed to growth at $0.2 \%$ so that this month's newborn have initial wealth which is 1.002 times the initial wealth of last month's newborn. The riskfree rate and parameters of the Binomial process for the risky asset are chosen to match the sample moments for the U.S. economy over the period 1/59-12/91 (see Table 1). A rate of time preference of 1 is used. Further details are in Sections 1.3 and 2.2.

Results are based on 5 simulations of 10000 observations. $\gamma$ is the RRA coefficient and $1 / F$ is the data frequency. Further, $R^{z}(t, t+F)$ is risky asset return from $t$ to $(t+F)$ while $\bar{c}_{F}(t+1)$ is the sum of aggregate consumption from time $(\mathrm{t}+1)$ to time $(\mathrm{t}+\mathrm{F})$ and $\overline{\mathrm{c}}_{\mathrm{F}}{ }^{1}(\mathrm{t}+1)$ is the sum of consumption from time $(\mathrm{t}+1)$ to time $(\mathrm{t}+\mathrm{F})$ of the chosen class. Let $\sigma_{\mathrm{c}}\left(\gamma, \mathrm{T}_{\mathrm{C}}, \mathrm{T}_{\mathrm{I}}, \mathrm{F}\right)$ denote $\sigma\left[\bar{c}_{\mathrm{F}}(\mathrm{t}) / \bar{c}_{\mathrm{F}}(\mathrm{t}-\mathrm{F})\right]$ and $\rho_{\mathrm{cz}}\left(\gamma, \mathrm{T}_{\mathrm{C}}, \mathrm{T}_{\mathrm{I}}, \mathrm{F}\right)$ denote $\rho\left[\mathrm{R}^{\mathrm{z}}(\mathrm{t}, \mathrm{t}+\mathrm{F}),\left\{\bar{c}_{\mathrm{F}}(\mathrm{t}+1) / \bar{c}_{\mathrm{F}}(\mathrm{t}+1-\mathrm{F})\right\}\right]$, all for the economy with a consumption decision interval of $\mathrm{T}_{\mathrm{C}}$ and portfolio rebalancing every $\mathrm{T}_{\mathrm{I}}$ periods. 
Table 5 cont

Overlapping Generation 20 Year Life Model $\left(L T=240 ; g=1.002 ; T_{I} \geq 1, T_{C}=1\right.$ or $\left.T_{C}=T_{\nu}\right)$ : Moments for Aggregate Consumption

\begin{tabular}{|c|c|c|c|c|c|c|c|}
\hline & \multicolumn{3}{|c|}{ Parameters } & \multicolumn{2}{|c|}{ Moments $y\left(\gamma, T_{C}, T_{1}, F\right)$} & \multicolumn{2}{|c|}{$\mathrm{x}\left(\gamma, \mathrm{T}_{\mathrm{C}}, \mathrm{T}_{\mathrm{I}}, \mathrm{F}\right) / \mathrm{x}(\gamma, 1,1, \mathrm{~F})$} \\
\hline$\gamma$ & $\mathrm{T}_{\mathrm{C}}$ & $\mathrm{T}_{\mathrm{I}}$ & $\mathrm{F}$ & $\mathrm{y}=\mathrm{o}_{\mathrm{c}}$ & $\mathrm{y}=\rho_{\mathrm{cz}}$ & $\mathrm{x}=\sigma_{\mathrm{c}}$ & $\mathrm{x}^{=} \rho_{\mathrm{cz}}$ \\
\hline \multirow[t]{15}{*}{5} & 1 & 1 & 1 & 0.0195 & 0.9978 & 1.000 & 1.000 \\
\hline & & & 3 & 0.0281 & 0.7891 & 1.000 & 1.000 \\
\hline & & & 12 & 0.0559 & 0.6554 & 1.000 & 1.000 \\
\hline & 1 & 2 & 1 & 0.0194 & 0.9977 & 0.998 & 1.000 \\
\hline & & & 3 & 0.0285 & 0.7924 & 1.017 & 1.004 \\
\hline & & & 12 & 0.0575 & 0.6610 & 1.028 & 1.009 \\
\hline & 2 & 2 & 1 & 0.0137 & 0.7043 & 0.706 & 0.706 \\
\hline & & & 3 & 0.0272 & 0.6208 & 0.971 & 0.787 \\
\hline & & & 12 & 0.0558 & 0.6017 & 0.998 & 0.918 \\
\hline & 1 & 3 & 1 & 0.0194 & 0.9978 & 0.997 & 1.000 \\
\hline & & & 3 & 0.0283 & 0.7882 & 1.010 & 0.999 \\
\hline & & & 12 & 0.0555 & 0.6440 & 0.992 & 0.983 \\
\hline & 3 & 3 & 1 & 0.0112 & 0.5733 & 0.577 & 0.575 \\
\hline & & & 3 & 0.0258 & 0.4861 & 0.919 & 0.616 \\
\hline & & & 12 & 0.0566 & 0.5698 & 1.013 & 0.869 \\
\hline \multirow[t]{15}{*}{8} & 1 & 1 & 1 & 0.0122 & 0.9979 & 1.000 & 1.000 \\
\hline & & & 3 & 0.0177 & 0.7905 & 1.000 & 1.000 \\
\hline & & & 12 & 0.0348 & 0.6533 & 1.000 & 1.000 \\
\hline & 1 & 2 & 1 & 0.0121 & 0.9979 & 0.998 & 1.000 \\
\hline & & & 3 & 0.0177 & 0.7879 & 1.002 & 0.997 \\
\hline & & & 12 & 0.0347 & 0.6545 & 0.997 & 1.002 \\
\hline & 2 & 2 & 1 & 0.0086 & 0.7042 & 0.707 & 0.706 \\
\hline & & & 3 & 0.0170 & 0.6206 & 0.965 & 0.785 \\
\hline & & & 12 & 0.0352 & 0.6142 & 1.010 & 0.940 \\
\hline & 1 & 3 & 1 & 0.0121 & 0.9974 & 0.998 & 0.999 \\
\hline & & & 3 & 0.0179 & 0.7891 & 1.012 & 0.998 \\
\hline & & & 12 & 0.0354 & 0.6518 & 1.017 & 0.998 \\
\hline & 3 & 3 & 1 & 0.0070 & 0.5779 & 0.579 & 0.579 \\
\hline & & & 3 & 0.0162 & 0.4876 & 0.915 & 0.617 \\
\hline & & & 12 & 0.0349 & 0.5592 & 1.002 & 0.856 \\
\hline
\end{tabular}




\section{Table 6}

Ratios of moments for aggregate consumption in an overlapping generation, twenty year life model in which power utility individuals make consumption and investment decisions every $\mathrm{T}$ periods and there are two risky assets. For a given data frequency, a consumption observation for the aggregate can be calculated each period; every observation is used to calculate moments. Further detail on how these moments are calculated is in Section 3.4.

Regarding the economy simulated, newborn's initial wealth is assumed to growth at $0.2 \%$ so that this month's newborn have initial wealth which is 1.002 times the initial wealth of last month's newborn. Parameters of the four state Multinomial process for the two risky assets are chosen so that the first asset's return $\mathrm{R}^{1}$ has the same distribution as the risky asset in Tables 3 to 5 and the second asset's one period return $R^{2}(t, t+1)$ has a specified mean $\mu_{2}$, skewness $\eta_{2}$, standard deviation $\sigma_{2}$ and correlation with the first asset $\rho_{12}$. The second asset's mean is set at 1.0023 and the skewness to 0 while the other two moments are allowed to vary as described below. The riskless rate and moments of the first asset's return are chosen to match the sample moments for the U.S. economy over the period 1/59-12/91 (see Table 1). A rate of time preference of 1 is used. Further details are contained in Sections 1.1 and 2.2.

Results are based on 5 simulations of 10000 observations. $\gamma$ is the RRA coefficient and $1 / F$ is the data frequency. Further, $R^{1}(t, t+F)$ is the first risky asset return from $t$ to $(t+F)$ while $\bar{c}_{F}(t+1)$ is the sum of aggregate consumption from time $(t+1)$ to time $(t+F)$ and $\bar{c}_{F}^{1}(t+1)$ is the sum of consumption from time $(t+1)$ to time $(t+F)$ of the chosen class. Define $\Theta=\left(\gamma, \sigma_{2}, \rho_{12}\right)$ and let $\sigma_{c}\left(\Theta, T_{I}, T_{C}, F\right)$ denote $\sigma\left[\bar{c}_{F}(t) / c_{F}(t-F)\right]$ and $\rho_{c 1}\left(\Theta, T_{I}, T_{C}, F\right)$ denote $\rho\left[R^{1}(t, t+F),\left\{\bar{c}_{F}(t+1) / c_{F}(t+1-F)\right\}\right]$ where $T_{I}$ is the investment decision interval and $\mathrm{T}_{\mathrm{C}}$ is the consumption decision interval. 


\section{Table 6 cont}

Overlapping Generation 20 Year Life Model $\left(L T=240 ; g=1.002 ; \quad T_{I}=T_{C}=T\right):$ Moments for Aggregate Consumption

\begin{tabular}{|c|c|c|c|c|c|c|}
\hline \multicolumn{5}{|c|}{ Parameters $(\Theta, T)$} & \multicolumn{2}{|c|}{$\mathrm{x}(\Theta, \mathrm{T}, \mathrm{T}, \mathrm{F}) / \mathrm{x}(\Theta, 1,1, \mathrm{~F})$} \\
\hline$\gamma$ & $\rho_{12}$ & $\sigma_{2}$ & $\mathrm{~T}$ & $\mathrm{~F}$ & $\mathrm{x}=\boldsymbol{\sigma}_{\mathrm{c}}$ & $\mathrm{x}=\rho_{\mathrm{c} 1}$ \\
\hline \multirow[t]{6}{*}{5} & 0.2 & 0.0204 & 3 & 1 & 0.573 & 0.574 \\
\hline & & & & 3 & 0.896 & 0.615 \\
\hline & & & & 12 & 1.006 & 0.891 \\
\hline & & & 6 & 1 & 0.405 & 0.405 \\
\hline & & & & 3 & 0.738 & 0.364 \\
\hline & & & & 12 & 0.967 & 0.661 \\
\hline \multirow[t]{6}{*}{5} & 0.2 & 0.0102 & 3 & 1 & 0.577 & 0.582 \\
\hline & & & & 3 & 0.915 & 0.632 \\
\hline & & & & 12 & 1.001 & 0.876 \\
\hline & & & 6 & 1 & 0.400 & 0.411 \\
\hline & & & & 3 & 0.737 & 0.390 \\
\hline & & & & 12 & 0.964 & 0.702 \\
\hline \multirow[t]{6}{*}{5} & 0.4 & 0.0204 & 3 & 1 & 0.573 & 0.574 \\
\hline & & & & 3 & 0.895 & 0.609 \\
\hline & & & & 12 & 0.979 & 0.867 \\
\hline & & & 6 & 1 & 0.410 & 0.404 \\
\hline & & & & 3 & 0.746 & 0.364 \\
\hline & & & & 12 & 0.968 & 0.652 \\
\hline \multirow[t]{6}{*}{8} & 0.2 & 0.0204 & 3 & 1 & 0.573 & 0.572 \\
\hline & & & & 3 & 0.906 & 0.610 \\
\hline & & & & 12 & 0.976 & 0.846 \\
\hline & & & 6 & 1 & 0.410 & 0.406 \\
\hline & & & & 3 & 0.755 & 0.369 \\
\hline & & & & 12 & 0.953 & 0.653 \\
\hline
\end{tabular}




\section{Table 7}

Cost to an infinitely-lived individual with RRA coefficient $\gamma$ of making decisions every T months.

The riskfree rate and parameters of the Binomial process for the risky asset are chosen to match the sample moments for the U.S. economy over the period 1/59-12/91 (see Table 1). A rate of time preference of 1 is used. Further details are in Sections 2.2 and 5.

By making decisions every $T$ months, the individual enjoys a certain level of utility at the time of making a decision which depends on her wealth. If she made decisions every period, she could attain this level of utility with a reduced level of wealth. The reported cost is the fractional reduction in her wealth which would allow her to attain the same level of utility by making decisions every period.

\begin{tabular}{lllll}
\hline \hline$\gamma$ & \multicolumn{4}{c}{$\mathrm{T}=$} \\
\cline { 2 - 5 } & 1 & 3 & 6 & 12 \\
\hline \hline 3 & 0.00000 & 0.00168 & 0.0042 & 0.00919 \\
5 & 0.00000 & 0.00128 & 0.00318 & 0.00696 \\
8 & 0.00000 & 0.00098 & 0.00245 & 0.00533 \\
10 & 0.00000 & 0.00085 & 0.00212 & 0.00462 \\
\hline \hline
\end{tabular}




\section{Figure 1}

Decision Structure in the Overlapping Generations Economies with Decision Interval of $T$ and so T Classes of Individuals

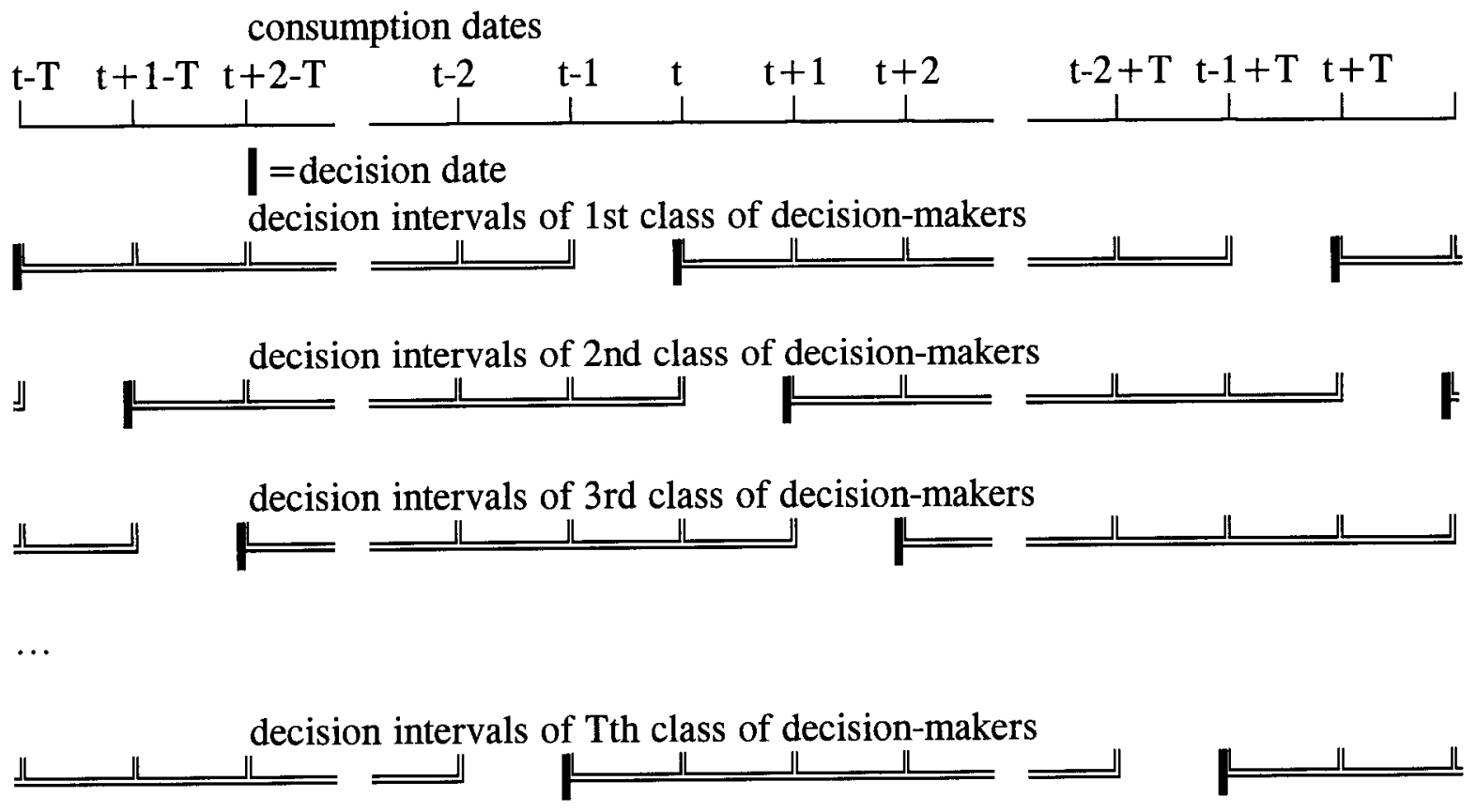


Figure 2

\section{$\bar{c}_{F}^{\prime}(t)$ from Table 2 versus $\bar{c}_{F}^{l}(t)$ from Table 3}

Aggregate consumption can be defined in two ways for the case in which decisions are made every $\mathrm{T}$ periods and all individuals make decisions at the same time. Representative agent consumption is the first definition $\left(\overline{\mathrm{c}}_{\mathrm{F}}^{\prime}(\mathrm{t})\right.$ from Table 2$)$ while the consumption of one class in the overlapping generations model of Section 1.1 is the second $\left(\overline{\mathrm{c}}_{\mathrm{F}}{ }^{1}(\mathrm{t})\right.$ from Table 3$) . \mathrm{F}$ is the data interval.

Panel A: $(F=3)$

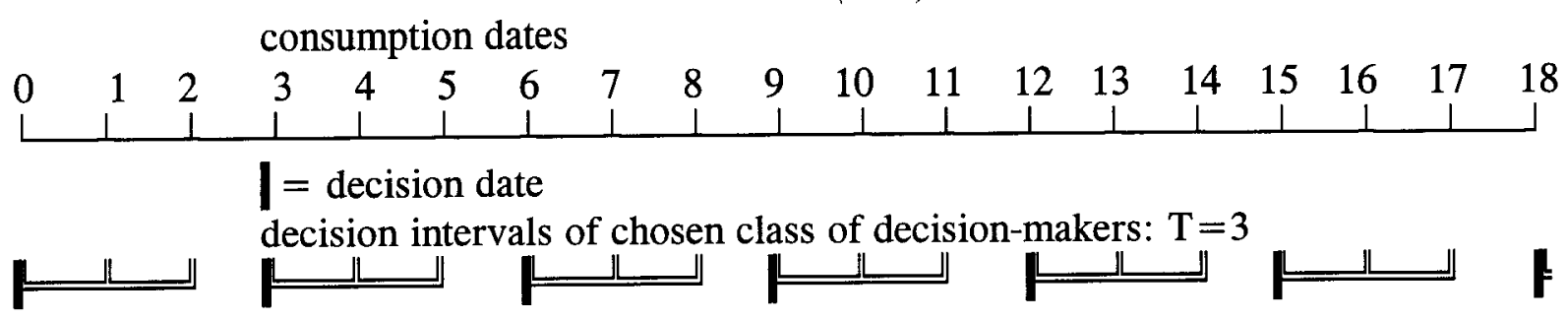

$\overline{\mathrm{c}}_{\mathrm{F}}{ }^{\prime}(\mathrm{t})$ from Table 2 (every Tth observation; each observation interval starts with a decision) $|-|-\infty$
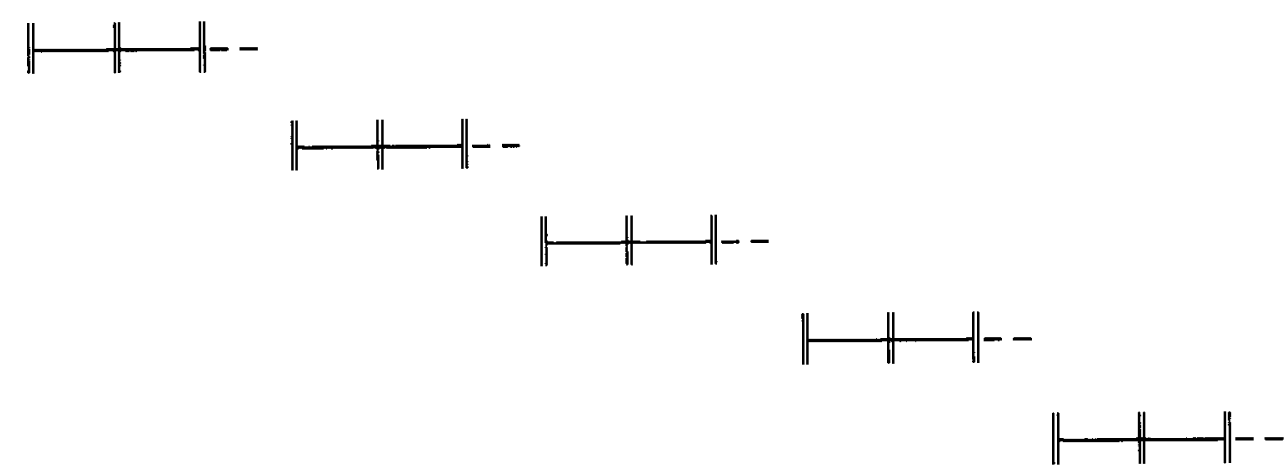

$\overline{\mathrm{c}}_{\mathrm{F}}^{1}(\mathrm{t})$ from Table 3 (every observation)

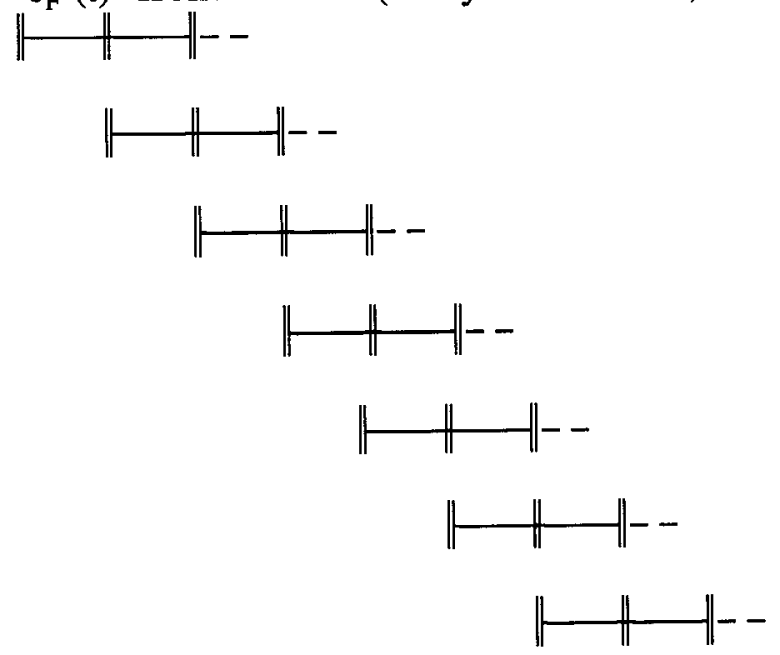


Figure 2 cont

Panel B: $F=12$

consumption dates

\begin{tabular}{cccccccccccccccccccc}
0 & 1 & 2 & 3 & 4 & 5 & 6 & 7 & 8 & 9 & 10 & 11 & 12 & 13 & 14 & 15 & 16 & 17 & 18 \\
& $\perp$ & $\perp$ & 1 & $\perp$ & $\perp$ & $\perp$ & $\perp$ & $\perp$ & $\perp$ & $\perp$ & $\perp$ & $\perp$ & $\perp$ & $\perp$ & $\perp$ & $\perp$ & $\perp$ & \\
\hline
\end{tabular}

= decision date

decision intervals of chosen class of decision-makers: $\mathrm{T}=3$

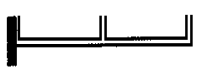

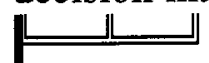

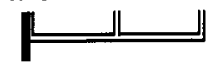

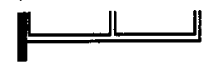

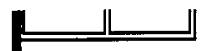

$\overline{\mathrm{c}}_{\mathrm{F}}{ }^{\prime}(\mathrm{t})$ from Table 2 (every Tth observation; observation interval starts with decision)

$\|$
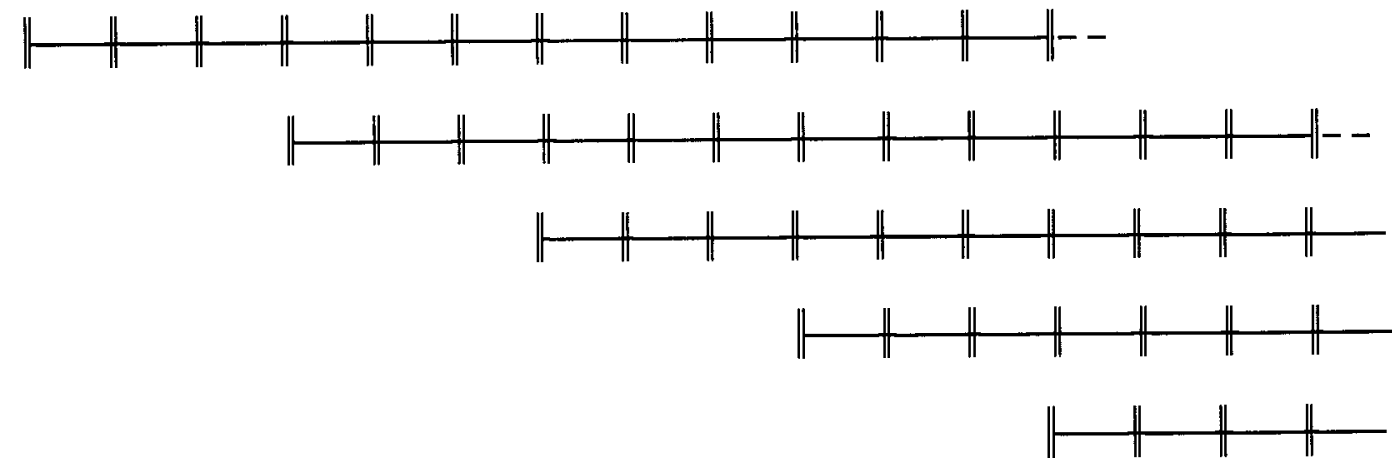

$\overline{\mathrm{c}}_{\mathrm{F}}^{1}(\mathrm{t})$ from Table 3 (every observation)

$\|$
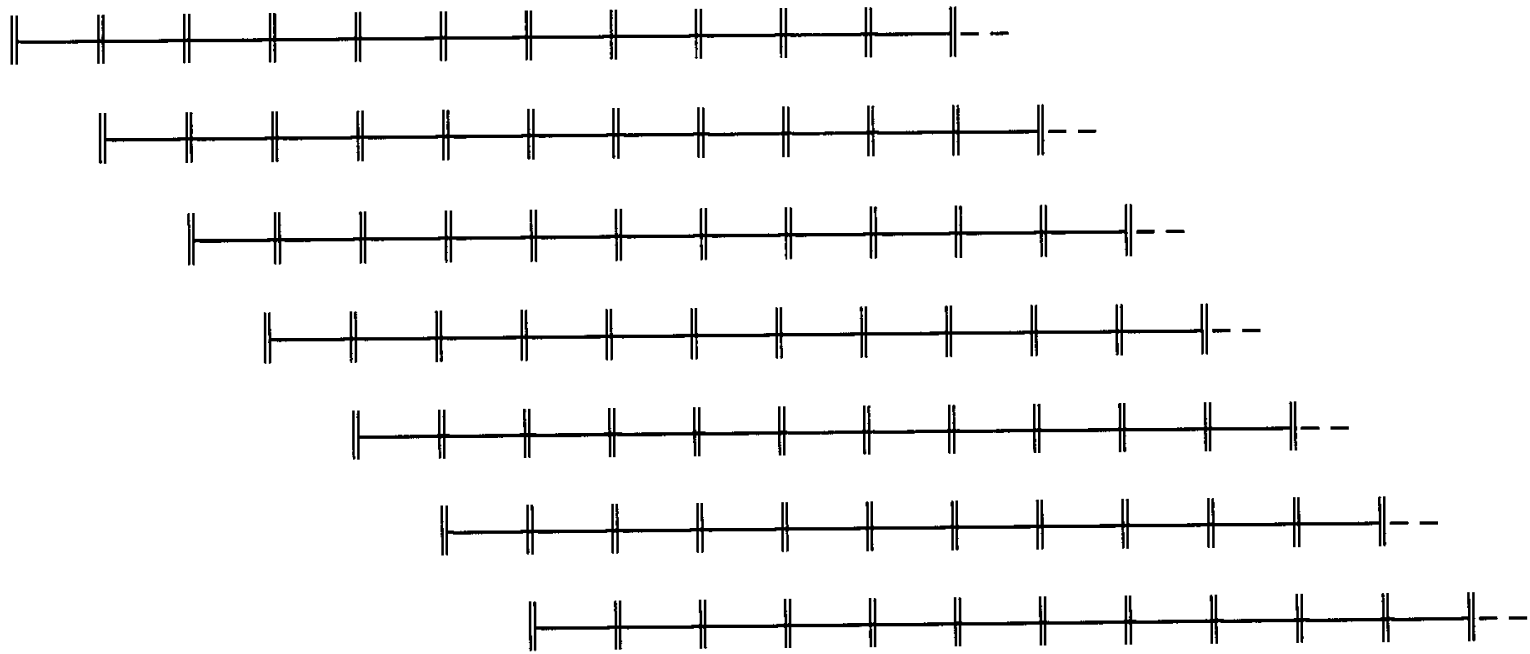
Figure 3

Volatility of Aggregate Consumption Growth ( $L T=240$ months; $g=1.002 ; \gamma=5 ; T_{I}=T_{C}=T$ )

Effect of varying the data interval $(\mathrm{F})$ and decision interval $(\mathrm{T})$ in the model described in section 1.1 in which an agent makes her nondurable consumption and portfolio rebalancing decisions simultaneously every T months. (1/T)th of the population makes a decision in any month. Agents have power utility with RRA of $\gamma$ and live for LT months. Each period one individual dies and is replaced by a newborn. The endowment for the newborn grows at a deterministic rate $\mathrm{g}$.

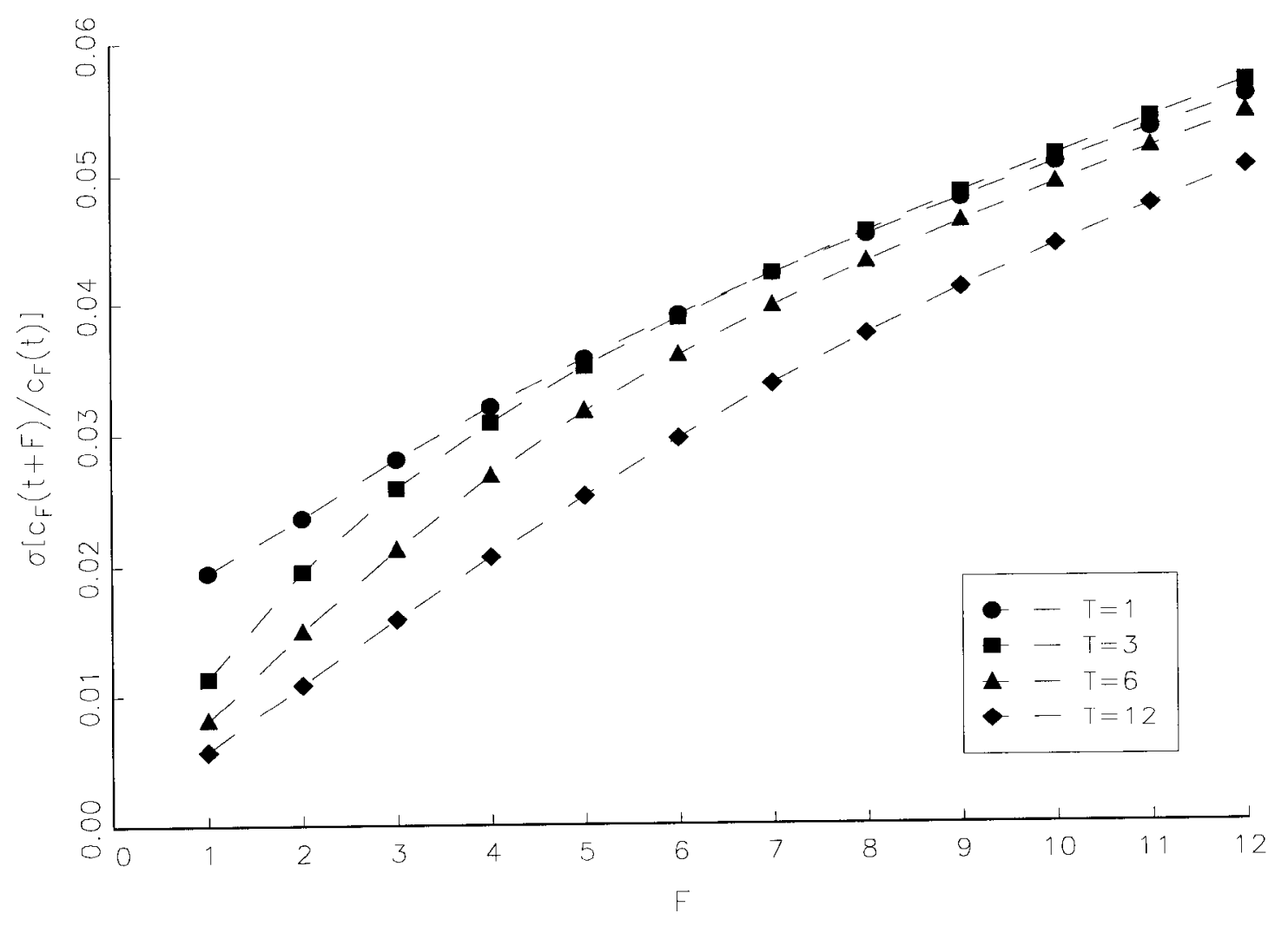


Figure 4

Correlation of Aggregate Consumption Growth and Risky Asset Return ( $L T=240$ months; $g=$ 1.002; $\gamma=5 ; T_{I}=T_{C}=T$ )

Effect of varying the data interval $(\mathrm{F})$ and decision interval $(\mathrm{T})$ in the model described in section 1.1 in which an agent makes her nondurable consumption and portfolio rebalancing decisions simultaneously every T months. (1/T)th of the population makes a decision in any month. Agents have power utility with RRA of $\gamma$ and live for LT months. Each period one individual dies and is replaced by a newborn. The endowment for the newborn grows at a deterministic rate $\mathrm{g}$.

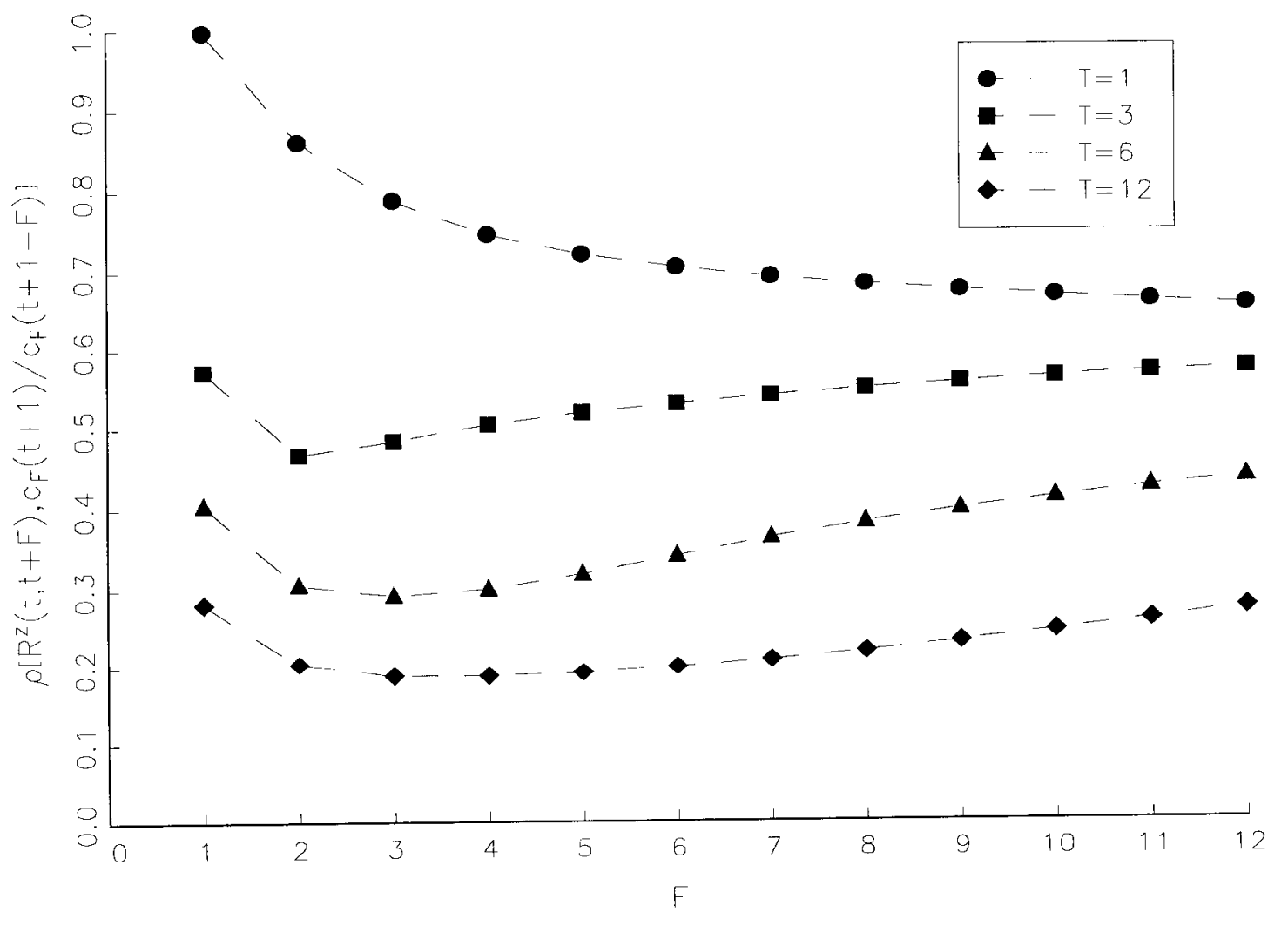

